\title{
CONTRIBUIÇÃO AO CONHECIMENTO DAS ALGAS DO GÊNERO EUGLENA (EUGLENOPHYCEAE) NO MUNICÍPIO DO RIO DE JANEIRO E ARREDORES, BRASIL ${ }^{1}$
}

Mariângela Menezes ${ }^{2}$.

Recebido em 07.01.88. Aceito em 02.02.89

RESUMO - Procedeu-se pioneiramente ao levantamento taxonômico das algas pigmentadas do gênero Euglena Ehr. (Euglenophyceae), baseado na análise de cerca de 150 amostras, coletadas de agosto de 1980 a novembro de 1982 em diversos corpos d'água acessíveis do Município do Rio de Janeiro e arredores, Brasil. Do total de amostras coletadas, 68 continham euglenóides pigmentados e destas, 36 mostraram representantes de Euglena. Foram identificados 17 táxons distribuídos em 14 espécies e 3 variedades, dos quais, apenas 8 já haviam sido documentados para o Estado do Rio de Janeiro, constituindo os demais primeiros novos registros de ocorrência na área estudada. Euglena agilis H.J. Cart. foi o táxon melhor representado em número de amostras, aparecendo em $22 \%$ das 36 amostras analisadas. Todos os táxons foram descritos, medidos, ilustrados e comentados com base em seus caracteres morfológicos vegetativos a partir de material vivo e, sempre que possível, em amostras populacionais. Acrescentaram-se ainda informações quanto à distribuição geográfica dos 17 táxons identificados no Estado do Rio de Janeiro bem como uma chave artificial indentada para identificação das espécies inventariadas. Complementam o trabalho 48 figuras, um mapa do Estado e outro do Município, contendo este indicação dos locais de coleta.

Palavras-chave: Algas, Euglenophyceae, Euglena pigmentadas.

ABSTRACT - A taxonomical survey was first carried out at a floristic inventory of the pigmented Euglena Ehr. (Euglenophyceae), based on the analisys of near 150 samples, collected from August 1980 to November 1982 at accessible bodies of water of the Municipality of Rio de Janeiro and surroundings, Brazil. Of the samples

1 - Parte da dissertaçāo de Mestrado apresentada ao Departamento de Botânica do Museu Nacional, Universidade Federal do Rio de Janeiro (UFRJ).

2 - Departamento de Botânica, Museu Nacional, UFRJ, Quinta da Boa Vista, São Cristovão, 20942, Rio de Janeiro, Brasil. 
collected, 68 contained specimens of pigmented euglenoids, of these 36 showed representatives of Euglena. Seventeen taxa were identified and distributed in 14 species and 3 varieties, of which 8 have already been identified for the State of Rio de Janeiro, being the others for the first time recorded in the area. Euglena agilis H. J. Cart. was the best represented taxon in number of samples studied, which occured in $22 \%$ of the 36 samples analized. Each taxon was described in detail, measured, illustrated and commented on the bases of vegetative morphology in living material and whenever possible studied from population samples. Information on geographic distribution of the 17 taxa in the State of Rio de Janeiro was provided, as well a indented artificial key for the recognition of species and varieties identified. Forty eight illustrations, a map of the State and another of the Municipality to show the collecting sites, complement the text.

Keywords: Algae, Euglenophyceae, Pigmented Euglena.

\section{Introdução}

Euglenophyceae apresenta-se, entre os grupos de algas unicelulares de ambientes continentais, como um dos mais importantes, desenvolvendo-se, principalmente, em águas com elevados teores de matéria orgânica, fósforo e nitrogênio (Round, 1973), destacando-se, por isso na hidrobiologia aplicada, como excelentes indicadores de águas poluídas (Palmer, 1969). Além disso, as Euglenophyceae desenvolvem-se em ambientes os mais variados, formando a comunidade epipélica de ambientes aquáticos eutróficos, participando junto com outros fitoflagelados das comunidades neustônica e planctônica de corpos d'água, crescendo sobre cascas e folhas de árvores e em meio a secreções mucosas de animais aquáticos, vivendo como organismos epizóicos em brânquias de peixes, como endozóicos no intestino de anfíbios e como parasitas de crustáceos planctônicos (Leedale, 1967; Bourrelly, 1970).

Abrangendo cerca de 700 espécies, entre pigmentadas e apigmentadas, a família Euglenaceae compreende indivíduos unicelulares, flagelados, de hábito isolado, raramente fixos ou ainda sob a forma de colônias. As células podem ser nuas ou estar no interior de lóricas e, com exceção do gênero Cryptoglena Ehrenberg, apresentam paramido como a principal substância de reserva. A reprodução sexuada no grupo não está confirmada e a multiplicação vegetativa em estádio móvel ou palmelóide ocorre, geralmente, por divisões longitudinais. A bibliografia sobre os representantes pigmentados da família Euglenaceae é reduzida, havendo sido registrados até o presente 71 táxons infragenéricos, num total de 21 trabalhos, dos quais 13 limitam-se apenas a listagem dos táxons, sem descrições nem ilustrações.

A primeira publicação sobre Euglenaceae pigmentadas no Estado do Rio de Janeiro é a de Prowazek (1910), que lista entre outros apigmentados, 6 táxons desta família, baseado em material coletado nos arredores de Manguinhos, 
Estado do Rio de Janeiro e em pontos da cidade de São Paulo, Estado de São Paulo.

Entretanto, é com o trabalho de Cunha (1913a) que se inicia o estudo sistemático desse grupo de algas no Estado do Rio de Janeiro. Este autor faz o levantamento de 108 táxons de protozoários de água doce, documentados até então para o Brasil e acresce 113 novos registros de ocorrência, procedentes de coletas efetuadas em vários Estados: Ceará, Minas Gerais, Piauí, Rio de Janeiro, Santa Catarina e São Paulo. Dos 113 novos registros, 46 são de euglenáceas pigmentadas, identificadas a partir de material coletado em Manguinhos, Gávea e Cascadura, Estado do Rio de Janeiro e 8 constituem-se em espécies novas para a Ciência. Os táxons são acompanhados de distribuição geográfica e chave dicotômica de identificação para as espécies novas. Ainda no ano de 1913, este mesmo trabalho é reimpresso com as ilustrações (Cunha, 1913b) e também publicado de maneira sumária, nas Memórias do Instituto Oswaldo Cruz (Cunha, 1913c).

Em 1914, Cunha faz nova contribuição ao conhecimento dos protozoários brasileiros, com descrição de 5 novas espécies de euglenáceas pigmentadas, novamente, com descrição baseado em material coletado em Manguinhos, Rio de Janeiro (Cunha, 1914).

Posteriormente os demais táxons pigmentados de euglenáceas citados no Estado aparecem, na maioria, listados entre outros táxons de algas, com enfoques basicamente hidrobiológicos: Kolkwitz (1933), Oliveira et al. (1951), Andrade (1953, 1956), Oliveia et al. (1967), Calazans (1971), Semeraro \& Costa (1972), Alvarenga et al. (1979), Araújo (1979) e Araújo \& Maciel (1979), Sampaio (1984) e Huszar \& Esteves (1988). Somente os trabalhos de Peixoto \& Huszar (1983) Huszar (1985), Huszar (1986), Menezes (1987) e Huszar et al. (1988) registraram novos táxons de Euglenaceae pigmentadas, através de descrições e ilustrações.

Ầ exceção dos trabalhos de Calazans (1971), Peixoto \& Huszar (1983), Huszar (1985) e Menezes (1987) os demais documentam um total de 17 táxons representantes do gênero Euglena para o Estado do Rio de Janeiro.

O presente trabalho foi desenvolvido sabendo-se que no Município do Rio de Janeiro e arredores (mapas 1,2) existe um grande número de ambientes propícios ao desenvolvimento deste grupo de algas e de que pouco ou quase nada se conhece, atualmente sobre as Euglenaceae pigmentadas nesta área. Assim, objetivou-se, com este estudo pioneiro, contribuir ao conhecimento dessas algas e, conseqüentemente, da ficoflórula dulciaqüícola do Estado do Rio de Janeiro.

\section{Material e Métodos}

Nas 150 amostras analisadas foram utilizados os seguintes métodos de coletas: filtragem através de rede de plâncton confeccionada em nailon, com aber- 
tura de malha de ca. de $25 \mu \mathrm{m}$; passagem do frasco aberto na superfície da água; raspagem de solo e paredões úmidos; raspagem de objetos e de partes de vegetais aquáticos e coleta de lodo do fundo de corpos d'água.

Cada amostra foi dividida em duas partes, sendo uma delas imediatamente fixada e preservada em Solução de Transeau (Bicudo e Bicudo, 1970) e a outra conservada viva para posterior análise dos caracteres morfológicos. As amostras foram estocadas em frascos de vidro incolor, marca "Wheaton", com tampa de pressão de polietileno, com capacidade de $65 \mathrm{ml}$.

Foram montadas aproximadamente 15 lâminas de cada uma das 150 amostras coletadas, totalizando perto de 22500 indivíduos observados. Todo o material foi examinado vivo à exceção de $E$. caudata Hübn. e $E$. granulata (Klebs) Schmitz, em amostras populacionais, entre lâmina e lamínula em microscópio binocular com contraste-de-fase, de marca Carl Zeiss Oberkochen, modelo Standard 18; os desenhos e as medidas foram efetuados respectivamente, com auxílio de câmara-clara e de ocular micrometrada da mesma marca, acoplados ao sistema óptico do microscópio.

$\mathrm{Na}$ imobilização dos indivíduos ou redução dos movimentos dos euglenóides, utilizou-se solução aquosa a 1\% de "KARO" ou solução aquosa a $25 \%$ de glicerina, como meio de montagem e densificação.

$\mathrm{Na}$ evidenciação das estruturas celulares foram utilizadas solução aquosa a $1 \%$ de vermelho-neutro para corpos mucíferos, solução aquosa a $25 \%$ de hematoxilina de Heidenhain para pirenóides e solução aquosa a $1 \%$ de carmim acético para núcleo.

Seguiu-se para identificação sistemática do gênero, os trabalhos de Dangeard (1901), Gojdics (1953) e Pringshein (1956) bem como os trabalhos gerais de Skuja $(1948,1956)$, Huber-Pestalozzi (1955), Leedale (1967) e Cardoso (1982).

Todas as amostras utilizadas no trabalho acham-se depositadas no Herbário Ficológico do Museu Nacional (R), Universidade Federal do Rio de Janeiro, Rio de Janeiro, sendo relacionadas em material examinado somente aquelas que continham representantes do gênero Euglena:

- Município do Rio de Janeiro, São Cristovão, Quinta da Boa Vista, Museu Nacional, Horto Botânico, tanque de cimento com vegetação de Pontederiaceae, rede de plâncton, col. M. Menezes, 04. VIII. 1980, (R 147068); Município do Rio de Janeiro, São Cristovão, Quinta da Boa Vista, Museu Nacional, Horto Botânico, tanque de cimento com vegetação de Eichhornia sp. em frente ao laboratório de Malacologia, passagem de frasco, col. M. Menezes, 11.XII.1980, (R 147069); Município do Rio de Janeiro, São Cristovão, Quinta da Boa Vista, Jardim Zoológico, Parque dos Veados, lago artificial com vegetação de Lemna sp., passagem de frasco, col. M. Menezes, 16.XII.1980, (R 147070); Município do Rio de Janeiro, São Cristovão, Quinta da Boa Vista, Jardim Zoológico, Lago dos Cisnes, lago com troncos e folhas em decomposição, passagem de frasco e coleta de lodo, col. M. Mene- 
zes, 16.XII.1980, (R 147071); Município do Rio de Janeiro, São Cristovão, Quinta da Boa Vista, Jardim Zoológico, Lago dos Guarás, lago com vegetação de Araceae, Liliaceae e Amárylidaceae, espremido de raízes e passagem de frasco, col. M. Menezes, 16.XII.1980, (R 147074); Município do Rio de Janeiro, São Cristovão, Quinta da Boa Vista, Jardim Zoológico, tanque da Jaula dos Pinguins, passagem de frasco, col. M. Menezes, 16.XII.1980, (R 147075); Município do Rio de Janeiro, Alto da Boa Vista, Floresta da Tijuca, Açude da Solidão, lago artificial com vegetação de Zingiberaceae, rede de plâncton e coleta de lodo, col. M. Menezes, 24.III.1981, (R 147077); Munić́pio do Rio de Janeiro, Alto da Boa Vista, Floresta da Tijuca, Açude da Solidão, raspagem de paredão úmido, col. M. Menezes, 24. III.1981, (R 147079); Município do Rio de Janeiro, Jacarepaguá, Canal das Tachas, rede de plâncton, col. Departamento de Conservação Ambiental (DECAM-FEEMA), 25.V.1981, (R 147080); Município do Rio de Janeiro, Jacarepaguá, Cidade de Deus, lagoa de estabilização, rede de plâncton a $10 \mathrm{~cm}$ de profundidade, col. M.L.J. Melo, 24.VI.1981, (R 147081); Município do Rio de Janeiro, Rodovia BR-116, km 139, Rio Roncador, vegetação de Alismataceae, Nymphaeaceae, Menyanthaceae e Pontederiaceae, espremido de raízes e rede de plâncton, col. M. Menezes, 12.VIII.1981, (R. 147083); Município do Rio de Janeiro, Av. Brasil, Inhoaíba, Rio Campinho, margem ressecada formando pequenos empoçados com massa de algas filamentosas, passagem de frasco, coleta de lodo e recolhimento de fios, col. M. Menezes, 06.IX.1981, (R 147088); Município do Rio de Janeiro, Santa Cruz, Rua Projetada Salles, vala com dejetos orgânicos, água fétida, passagem de frasco, col. M. Menezes, 06.IX.1981, (R 147089); Município de Miguel Pereira, Rodovia RJ-125, córrego marginal à estrada, passagem de frasco, col. I.C.A. Dias, 07.IX.1981, (R 147090); Município do Rio de Janeiro, Santa Cruz, Rua Felipe Cardoso, no 2718, vala com massa de algas filamentosas, passagem de frasco e recolhimento de fios, col. M. Menezes, 09.X.1981, (R 147091); Município do Rio de Janeiro, Augusto Vasconcelos, Rua João Garcia Júnior, lote 10, empoçado com massa de algas, água fétida, passagem de frasco e recolhimento de fios, col. M. Menezes, 09.X.1981, (R 147093); Município do Rio de Janeiro, Paciência, Rua Urucânia, no 474, vala com dejetos orgânicos, águas fétida, passagem de frasco, col. M. Menezes, 09.X.1981, (R 147095); Município do Rio de Janeiro, Santíssimo, Av. Santa Cruz, no 11245, vala com dejetos orgânicos, água fétida, passagem de frasco e lodo de fundo, col. M. Menezes, 09.X.1981, (R 147096); Município do Rio de Janeiro, BR-101, Estrada da Pedra, em frente ao Centro Tecnológico do Exército, pântano, raspagem de solo e rede de plâncton, col. M. Menezes \& P.R.J. Brito, 15.X.1981, (R 147098); Município do Rio de Janeiro, Jacarepaguá, Taquara, Estrada do Rio Pequeno, Rio Pequeno, vegetação de Cyperaceae, Pontederiaceae e Gramineae, espremido de raízes e passagem de frasco, col. M. Menezes \& P.R.J. Brito, 15.X.1981, (R 147099); Município de Itaguaí, Coroa Grande, Av. 
Amaral Peixoto, vala passagem de frasco, I.C.A. Dias \& J.A. Peixoto, 22.I.1982, (R 147106); Município do Rio de Janeiro, Laranjeiras, Parque Guinle, lago artificial, raspagem de solo, rede de plâncton e lodo de fundo, col. M. Menezes, 27.IV.1982, (R 148116); Município do Rio de Janeiro, Flamengo, Rua Senador Vergueiro, no 66, lago artificial com massa de algas filamentosas, passagem de frasco e recolhimento de fios, col. M. Menezes, 23.V.1982, ( $R$ 148119); Município do Rio de Janeiro, Laranjeiras, Parque Guinle, lago artificial, lodo de fundo, col. M. Menezes, 26.V.1982, ( $R$ 148120); Município do Rio de Janeiro, Alto da Boa Vista, Floresta da Tijuca, Cascatinha, represamento, raspagem de solo e passagem de frasco, col. M. Menezes \& M.P. Rufier, 21.VII.1982, (R 148124); Município do Rio de Janeiro, Barra da Tijuca, Rodovia Rio-Santos, $\mathrm{Km} 2$, alagado com vegetação de Sagitta sp. e Nymphaea sp., espremido de raízes e passagem de frasco, col. M. Menezes \& M.P. Rufier, 21.VII.1982, (R 148125); Município do Rio de Janeiro, Vila Isabel, Av. Visconde de Santa Isabel, Parque Viveiros de Vila Isabel, lago artificial, passagem de frasco e lodo de fundo, col. M. Menezes \& M.P. Rufier, 21.VH.1982, (R 148126); Município de Araruama, São Vicente de Paulo, Lagoa Juturnaíba, próximo ao Rio Capivari, espremido de Salvinia, sp. e raspagem de folhas de Phragmites sp., col. M. Menezes \& M.P. Rufier, 31.VII.1982, (R 148128); Município do Rio de Janeiro, Alto da Boa Vista, Furnas, empoçado, passagem de frasco, col. E. Szabó, 26.IX.1982, (R 148132); Município do Rio de Janeiro, Jacarepaguá, Granja Calábria, empoçado, passagem de frasco e lodo de fundo, col. T.F. da Silva, 23.VIII.1982, (R 148133); Município do Rio de Janeiro, Jacarepaguá, Canal do Cortado, passagem de frasco, col. T.F. da Silva, 23.VII.1982, (R 148134); Município do Rio de Janeiro, Jacarepaguá, Granja Calábria, empoçado, passagem de frasco, col. T.F. da Silva. 23.VIII.1982, (R 148135); Município do Rio de Janeiro, Alto da Boa Vista, Furnas, empoçado, passagem de frasco, col. E. Szabó, 26.IX.1982, (R 148136); Município do Rio de Janeiro, Muda, Rua São Miguel, no 137, empoçado com massa de algas filamentosas, passagem de frasco e recolhimento de fios, col. E. Szabó, 26.IX.1982, (R 148137); Município do Rio de Janeiro, Alto da Boa Vista, Furnas, empoçado com massa de algas filamentosas, passagem de frasco e recolhimento de fios, col. E. Szabó, 26.IX.1982, (R 148138); Município do Rio de Janeiro, Laranjeiras, Parque Guinle, lago artificial, raspagem de solo e lodo de fundo, col. M. Menezes, 10.XI.1982, (R 148140); Município do Rio de Janeiro, Laranjeiras, Parque Guinle, lago artificial com pequena queda d'água, raspagem de paredão úmido, col. M. Menezes, 19.XI.1982, (R 148140).

\section{Resultados}

O gênero Euglena Ehr. apresenta células nuas, assimétricas, geralmente alongadas, com ou sem processo caudal e, quando em secção transversal, mos- 
tram-se elípticas, arredondadas, raramente trirradiadas. $\mathrm{O}$ periplasto é, frequentemente, estriado, acompanhado por grânulos ou verrugas e varia de semirígido a fortemente flexível. O flagelo emergente é ondulado e a abertura do canal é subapical (Bourrelly, 1970).

Os cloroplastídos podem ser discóides, em escudo, lenticulares, franjados ou em forma de fita, com ou sem pirenóides, estes últimos do tipo nu, interno ou duplos. Os grãos de paramido variam de globosos, arredondados, alongados, anulares, bastões a até discóides alongados (Leedale, 1967).

Algumas espécies Euglena acumulam hematocromo, que podem mascarar a cor verde dos cloroplastídios (Bourrelly, 1970).

Abrangendo cerca de 100 a 130 espécies, o gênero apresenta a sua maior incidência em ambiente de águas doces ricas em matéria orgânica, mas ocorre também em ambientes marinho e salobro (Leedale, 1967).

Em função do alto grau de variabilidade dos táxons infra-específicos do gênero, bem como a instabilidade de certas características utilizadas na sistemática do grupo, tais como intensidade de estriação do periplasto, quantidade de corpos mucíferos e de grãos de paramido, presença ou não de hematocromo e comprimento do flagelo, tentou-se estabelecer, baseado em Pringsheim (1956), caracteres mais estáveis que os citados anteriormente para a determinação dos táxons inventariados. Tais características em ordem crescente de importância taxonômica, foram: forma dos cloroplastídios, ausência ou presença bem como o tipo de pirenóides e forma e dimensões celulares.

Chave para identificação das espécies variedades de Euglena

1. Cloroplastídios em escudo ou discóides, com pirenóides.

2. Presença de duplopirenóides; células amplamente fusiformes.

3. Cloroplastídios 2, em escudo, parietais, laterais E.agilis

3'. Cloroplastídios 8 a 25 , discóides, parietais, distribuídos por toda a célula.

4. Cloroplastídios 10 a 25 , margens curvadas em direção ao periplasto; células $60,0-92,8 \times 8,0-20,0 \mu \mathrm{m}$.

5. Cloropastídios 10 a 12; corpos mucíferos evidentes como granulações refringentes, distribuidos em linhas contínuas entre as estrias do periplasto .......................................................... E. granulata

5'. Cloroplastídios 20 a 25; corpos mucíferos não evidentes como granulações refringentes, distribuídos entre as estrias do periplasto

E. caudata

4'. Cloroplastídios de 8 a 10, margens não curvadas em direção ao periplasto; células 37,0-44,0 X 9,0-13,0 $\mathrm{m}$ E.gracilis

2'. Presença de pirenóides nus; células estreitamente fusiformes a cilíndricas.

6. Cloroplastídios 8 a 10, discóides, margens curvadas em direção ao periplasto; células estreitamente fusiformes, pólo posterior atenuado gradativamente E: mutabilis var. mutabilis

6'. Cloroplastídios 25 a 30, discóides, margens não curvadas em 
direção ao periplasto; células cilíndricas, pólo posterior atenuado abruptamente E. deses

1. Cloroplastídios discóides ou lenticulares, ser pirenóides.

7. Cloroplastídios discóides; células fusiformes.

8. Células 50,5-64,4 X 9,2-11,5 $\mu \mathrm{m}(\mathrm{Rc} / 1=5,5-5,6)$ E. limnnophila

8'. Células 124,2-300,0 X 8,0-14,0 $\mu \mathrm{m}(\mathrm{Rc} / 1=9,6-31,2)$.

9. Células $124,2-165,0 \times 11,5-14,0 \mu \mathrm{m}(\mathrm{Rc} / 1=9,6-11,8)$

E. acus var. acus

9'. Células 250,0-300,0 X 8,0-13,0 $\mu \mathrm{m}(\mathrm{Rc} / 1=23-31,2)$

E. acus var. longissima

7. Cloroplastídios discóides ou lenticulares; células cīlíndricas.

10. Cloroplastídios discóides; periplasto estriado e com verrugas.

11. Verrugas esféricas; células 82,4-128,0 X 9,2-15,5 $\mu \mathrm{m}$ $(\mathrm{Rc} / 1=8,2-9,0)$................................ E. spirogyra var. spirogyra

11'. Verrugas poligonais; células 184,0-252,0 X 22,0-26,0 $\mu \mathrm{m}$ $(\mathrm{Rc} / 1=9,4-9,7)$

E. spirogyra var. fusca

10. Cloroplastídios discóides ou lenticulares; periplasto apenas estriado.

12. Cloroplastídios discóides; célula torcidas ou não; 2 grãos de paramido anulares, 1 anterior e outro posterior ao núcleo.

13. Secção transversal trirradiada

E. tripteris

13'. Secção transversal elíptica

E. oxyuris var. charkowiensis

12'. Cloroplastídios discóides ou lenticulares; células nunca torcidas; mais de 2 grãos de paramido anulares, arredondados ou em bastão, dispostos irregularmente no citoplasma.

14. Cloroplastídios discóides; pólo posterior atenuado; 6 grãos de paramido anulares (10,0-20,0 X 3,8-5,0 $\mu \mathrm{m}$

E. intermedia

14'. Cloroplastídios lenticulares; pólo posterior arredondado; grãos de paramido rumerosos, anulares, arredondados, alongados (ca. $1 \mu \mathrm{m}$ diâm.)

E. ehrenbergii

1. Cloroplastídios franjados ou em fitas, com ou sem piróides.

15. Cloroplastídios franjados, com duplopirenóides

E. splendens

15'. Cloroplastídios em fitas, irradiando de um centro de paramido, sem pirenóides E. viridis 
Euglena acus Ehr. var. acus

Infus. 112, pl. 7, fig. 15. 1838.

(Fig. 4-5)

Células estreitamente fusiformes, porção mediana cilíndrica, 124,0-165,0 X 11,5-14,0 $\mu \mathrm{m}(\overline{\mathrm{R}} \mathrm{c} / 1=9,6-11,8)$, pólo posterior atenuado gradativamente, em processo caudal cônico, hialino; periplasto com estrias espiraladas, longitudinais ou levemente espiraladas, variando em intensidade; cloroplastídios numerosos, discóides, parietais, ca.3,5 $\mu \mathrm{m}$ diâm.; pirenóides ausentes; grãos de paramido 4-6, bastôes ou anéis alongados, 10-20 X 2-3,5 $\mu \mathrm{m}$, outros menores, 3,0-4,0 X 1,5 $\mu \mathrm{m}$ dispersos no citoplasma; corpos mucíferos não observados; núcleo central, elíptico, ca. 18,0 X 5,0 $\mu \mathrm{m}$ estigma alongado, granuloso, ca. 5,0 $X$ 2,0 $\mu \mathrm{m}$; flagelo ca. 1/3 o comprimento da célula; metabolia restrita a algamas torções da célula, processo caudal permanece usualmente reto; cistos e estádios palmelóides não observados.

Material examinado: R147068; R147080; R147081; R147090; R147091; R148125; R148126.

Distribuição geográfica no Estado do Rio de Janeiro: Araruama Lagoa de Juturnaiba (Huszar, 1986)

Conforme Gojdics (1953), E. acus Ehr. apresenta inumeras variedades com posicionamento sistemático duvidoso, por estarem baseadas em características bastante variáveis, tais como: quantidade dos grãos de paramido na célula, grau de metabolia e intensidade de estriação do periplasto.

Van Oye (1924) propôs reunir em uma única variedade de $E$. acus Ehr. as variedades minor Hansg. e rigida Hübn., assim como E. acutissima Lemm. e Phacus acutissima Bernard, pois tais táxons seriam, na realidade, diferentes estádios de desenvolvimento de um mesmo indivíduo.

Apesar de concordar com a existência de polimorfismo nesta espécie, Deflandre (1924a) estabelece-lhe quatro variedades baseadas no grau de metabolia, na intensidade de estriação do periplasto, nas dimensões celulares e, mais particularmente, na razão comprimento / largura celular. Tais variedades são: var. acus, var rigida Hübn., var. vanoyei Defl. e var. longissima Defl.

Pringsheim (1956) demonstra, através de cultivos de clones, a existência de grande número de formas intermediárias distintamente constantes, as quais variavam não somente no comprimento dos indivíduos, como também na sua razão média comprimento / largura e nas dimensões dos cloroplastídios, núcleo, estigma e flagelo.

Euglena acus Ehr. apresenta morfologia muito próxima de E. limnophila Lemm., sendo que suas maiores dimensões, 124,0-300,0 X 8,0-14,0 $\mu \mathrm{m}$ $\overline{(\mathrm{R}} \mathrm{c} / 1=9,6-31,2)$, a separa de $E$. limnophila Lemm., que mede 50,6-64,4 X 9,2-11,5 $\mu \mathrm{m}(\overline{\mathrm{R}} \mathrm{c} / 1=5,5-5,6)$.

Os resultados obtidos baseados no estudo do nosso material confirmam o grau de polimorfismo citado na literatura para $E$. acus Ehr., principalmente, quanto à metabolia e à intensidade de estriação do periplasto. 
Assim, com exceção das dimensões, nossos indivíduos encaixam-se nas circunscrições da variedade típica da espécie, da var. vanoyei Defl. e da var. longissima Defl. No entanto, as dimensões celulares e a $\bar{R} \mathrm{c} / 1$ enquadram-se nas citadas para $E$. acus Ehr. var. acus, que é de 91,0-180,0 X 8,0-14,0 $\mu \mathrm{m}$ $(\overline{\mathrm{R}} \mathrm{c} / 1=11,4-12,9)$.

Achamos que tal fato evidencia a necessidade urgente de criteriosa revisão dos caracteres taxonômicos utilizados na sistemática da espécie e de suas variedades.

Ainda que as observações de Van Oye (1924) não devam ser totalmente desprezadas, identificamos nossas algas com E. acus Ehr var. acus baseados somente nos limites métricos que estas apresentaram. Além disso constatamos, na mesma amostra $\mathrm{R} 148126$, espécimes mais longos, com diferença de intervalo métrico bastante significativa e que identificamos com E. acus Ehr. var. longissima Defl. Em nenhum instante observamos plantas com dimensões intermediárias entre os intervalos métricos dessas duas variedades.

Euglena acus Ehr. var. longissima Defl.

Revue algot. 1(3): 238, pl. 4, fig. 1-3. 1924a.

(Fig. 6-8)

Difere da variedade típica da espécie pelas maiores dimensões de comprimento da célula, 250,0-300,0 $\mu \mathrm{m}$, e maior $\overline{\mathrm{R}} \mathrm{c} / 1=23-31,3$.

Material examinado: R148126.

Distribuição geográfica no Estado do Rio de Janeiro; primeira citação da ocorrência da variedade.

Euglena acus Ehr. var. longissima Defl. difere de E. acus Ehr. var. acus pelas maiores dimensões do comprimento da célula, ao redor de 250,0-300,0 $\mu \mathrm{m}$ bem como da maior $\overline{\mathrm{R}} \mathrm{c} / 1=23-31,3$, enquanto a variedade típica mede 124,2-165, $\mathrm{G} \mu \mathrm{m}$ de comprimento e apresenta $\overline{\mathrm{R}} \mathrm{c} / 1=9,62-11,8$.

Os indivíduos identificados com E. acus Ehr. var. longissima Defl. apareceram em amostra em que também constatamos a presença de $E$. acus Ehr. var. acus. Este fato ajudou-nos a considerar a var. longissima Defl. como independente da variedade típica da espécie, pois o intervalo de diferença das dimensões do comprimento foi expressivo, não se observando indivíduos intermediários. A var. longissima Defl. apresentou razão média comprimento/largura igual a 27 e a variedade típica da espécie aproximadamente 10,7. Não concordamos, entretanto, com os outros critérios diferenciais adotados por Deflandre (1924a) para separar as duas variedades, tais como: maior ou menor rigidez do periplasto, quantidade de grãos de paramido e intensidade de estriação do periplasto. Conforme nossos comentários em E. acus Ehr. var. acus, tais critérios estão sujeitos a variação de condições ambientais e no nosso material procedente do Rio de Janeiro ambas variedades apresentaram-se com caracteres em comum e o mesmo grau de variabilidade. Conseqüentemente, identificamos nosso material com E. acus Ehr. var. longissima Defl. somente pelas dimensões 
de comprimento, que foram muito superiores às de E. acus Ehr. acus bem como razão média comprimento/largura para a primeira variedade.

Euglena agilis H.J. Cart.

Annls Mag. nat. Hist. 240, pl. 6, fig. 62.1856

(Fig. 30-32)

Células basicamente fusiformes, 20,0-33,0 X 7,0-10,0 $\mu \mathrm{m}$ $(\overline{\mathrm{R}} \mathrm{c} / 1=2,6-3,3)$, pólo posterior atenuado abruptamente formando ou não processo caudal; periplasto com estrias finais, quase imperceptíveis, espiraladas; cloroplastídios 2, em escudo, parietais, laterais, atingindo quase todo o comprimento da célula, ca. 18,0 $\mu \mathrm{m}$ compr.; duplopirenóides presentes; grãos de paramido numerosos, globosos, ca. 2,0 $\mu \mathrm{m}$ diâm., dispersos no citoplasma, concentrados sobre os pirenóides; corpos mucíferos não observados; núcleo posterior elíptico, ca. 5,0X2,0 $\mu \mathrm{m}$; estigma alongado, granuloso, 1,0-1,8X0,7 $\mu \mathrm{m}$; flagelo aproximadamente do comprimento da célula a 2 vezes mais longo; movimento flagelar ativo, deslocamento rápido em diversas direções; metabolia intensa provocando abaulamento anterior da célula; cistos e estádios palmelóides não observados.

Material examinado: R147069; R147089; R147095; R147099; R148124; R148132; R148136; R148138.

Distribuição geográfica no Estado do Rio de Janeiro: RIO DE JANEIRO: Manguinhos, Gávea, Santa Cruz (Cunha, 1913a, 1913b: 17, como Euglena pisciformis Klebs); DUQUE DE CAXIAS, local não especificado (Andrade, 1956:452, como Euglena pisciformis Klebs).

Euglena agilis H.J. Cart. é uma espécie bastante representativa do gênero do Estado do Rio de Janeiro, sendo facilmente identificada pelo seu pequeno tamanho e pelos dois cloroplastídios em escudo, quase do comprimento da célula com duplopirenóides.

Conforme a literatura especializada consultada, muitas são as espécies de pequeno tamanho e com duplopirenóides próximas a $E$. agilis $\mathrm{H}$.J. Cart., sendo que Prinsgsheim (1956) diferiu-as pelos seguintes caracteres: dimensões e razão comprimento/largura da célula e tamanho do estigma. O referido autor, porém, chama a atenção para a variabilidade que ocorre nesses caracteres e para o número de cloroplastídios que, segundo ele, encontram-se com descrições duvidosas. Pringsheim (1956) considera, por isso, tais espécies como provavelmente, expressões morfológicas de um mesmo táxon.

Em nossas observações no material do Rio de Janeiro, os números de cloroplastídios e de pirenóides foram características que sempre se apresentaram constantes. Entretanto, observamos pequena variabilidade na forma de célula, ora mais alongada, ora mais alargada e, conseqüentemente, variabilidade nas dimensões e na razão média comprimento/largura celulares. As células mais alargadas apresentaram dimensões entre $20,0-25,0 \times 10,0 \mu \mathrm{m}(\overline{\mathrm{R}} \mathrm{c} / 1=2-2,5)$, enquanto que as células mais alongadas apresentaram dimensões entre 
$28,0-33,0 \times 7,0 \mu \mathrm{m}(\overline{\mathrm{R}} \mathrm{c} / 1=4,7)$. Apesar desse intervalo de diferença, até que se efetuem estudos mais significativos quanto à variabilidade citada, identificamos nossas algas com $E$. agilis H.J. Cart.

Pringsheim (1948) considera $E$. pisciformis Klebs sinônimo de E. agilis H.J. Cart., principalmente, por conta do exame da ilustração original em Carter (1856: pl. 6, fig. 62), a qual foi reproduzida, embora aumentada, em Gojdics (1953: pl. 1, fig. 5c). Se tal exame justifica, por um lado, segundo Gojdics (1953:136), a atitude de Pringsheim (1948), por outro fornecerá, indubitavelmente, oportunidade para muitos lamentarem a necessidade de se abolir a combinação $E$. pisciformis Klebs da literatura, desde que Carter parece jamais ter publicado uma diagnose para $E$. agilis, enquanto que a de Klebs (1883) é adequada; e desde que a combinação $E$. pisciformis, de Klebs, é de uma espécie relativamente bastante comum e vem sendo utilizada por 70 anos na literatura especializada, qualquer mudança neste sentido, conclui Gojdics (1953), só seria destinada à confusão e, portanto, não a recomenda.

Entretanto, não existe conservação, conforme o Código Internacional de Nomenclatura Botânica (Stafleu et al., 1978; art. 14.1), para epítetos específi$\cos$, Euglena agilis tem uma descrição relativamente ampla e, conseqüentemente, bastante pobre, mas tem, a qual diz: "It is named from its active movements. It is futher characterized by its flask form, the enlarged end being posterior: by its double spherical nucleolar cell, and its short, blunt, caudal prolongation when this is present". Por isso, deve prevalecer a combinação E. agilis H.J. Cart. sobre E. pisciformis Klebs.

\section{Euglena caudata Hübn.}

Euglenaceen-Fl. Stralsund 5, fig. 5, 1886.

(Fig. 33-34)

Células basicamente fusiformes, 82,0-92,8X20,0 $\mu \mathrm{m}(\overline{\mathrm{R}} \mathrm{c} / 1=4-4,6)$; pólo posterior acuminado em processo caudal cônico, hialino; periplasto com estrias finas, nítidas, espiraladas; cloroplastídios 20-25, discóides, parietais, contorno irregular, margens lobadas, levemente curvadas para o periplasto, ca. 10,0 $\mu \mathrm{m}$ diâm.; duplopirenóides presentes, grãos de paramido escassos, alongados, dispersos no citoplasma, 0,5-1,3 $\mu n_{\text {i }}$ compr.; corpos mucíferos poucos, arredondados, distribuição irregular, entre as estrias do periplasto, mais concentrados na região anterior da célula; núcleo posterior, arredondado, ca. 10,0 $\mu \mathrm{m}$ diâm.; estigma alongado, granuloso, 4,2-5,6 $\mu \mathrm{m}$ compr.: flagelo do comprimento da célula, às vezes mais longo; metabolia acentuada, curvaturas freqüentes, assumindo formato semelhante à letra " $C$ ", extremidades às vezes tocando-se; cistos e estádios palmelóides não observados.

Material examinado: R147083.

Distribuição geográfica no Estado do Rio de Janeiro: primeira citação da ocorrência da espécie. 
Euglena caudata Hübn. É uma espécie que se apresenta muito controvertida na literatura consultada.

Hübner (1886) cita, na descrição original da espécie, a presença de 50 cloroplastídios e que, possivelmente, exista um número mais elevado dessas estruturas, além de flagelo do comprimento da célula. Chu (1946) descreve-a com número de cloroplastídios inferior ao de Hübner, entre 6 e 30, e com o flagelo duas vezes mais longo que o comprimento da célula. Este autor refere-se ainda à presença de corpos mucíferos dispostos entre as estrias do periplasto e propõe que $E$. caudata Hübn, seja uma forma de $E$. granulata (Klebs) Schmitz com corpos mucíferos menos desenvolvidos. Chu (1946) admite ainda $E$. flava Dang. como sinônimo de $E$. caudata Hübn., pela presença de hematocromo em ambas as espécies.

Para Gojdics (1953) E. flava Dang. é uma boa espécie, independente de $E$. caudata Hübn., pois as descrições da primeira não se referem à presença de cloroplastídios lobados como na segunda.

Pringshein (1956) coloca em dúvida a $E$. caudata Hübn. descrita por Chu (1946) ao se referir à mesma $E$. caudata Hübn. descrita por Hübner (1886), visto o número de cloroplastídios e o tamanho do flagelo mencionado por estes autores estarem muito distantes entre si.

Euglena cudata Hübn. aproxima-se morfologicamente muito de $E$. velata Klebs, sendo que a presença de cloroplastídios estrelados em $E$. velata Klebs é a principal característica que a separa de $E$. caudata Hübn.

Nossos exemplares, apesar de pouco numerosos, não se mostraram em qualquer instante com corpos mucíferos como os de $E$. granulata (Klebs) Schmitz, isto é, como grânulos refringentes. Esta última espécie foi também identificada para o Rio de Janeiro. Pelo contrário, os corpos mucíferos só puderam ser evidenciados mediante o uso de vermelho-neutro, quando constatamos sua maior concentração na região anterior da célula. Desta forma, não seguimos as idéias de Chu (1946) e identificamos $E$. caudata Hübn. independentemente de $E$. granulata (Klebs) Schmitz, apesar da aproximação morfológica das duas espécies, até que se delimite melhor a posição sistemática dos dois táxons.

Euglena deses Ehr.

Infus. 107, pl. 7, fig. 8. 1838

(Fig. 36)

Células cilíndricas, bruscamente atenuadas em direção aos pólos, $109,0-130,0 \times 12,5-15,0 \mu \mathrm{m}(\overline{\mathrm{R}} \mathrm{c} / 1=8,6-9,08)$; pólo posterior atenuado abruptamente em processo caudal cilíndrico, hialino; periplasto com estrias finas, pouco perceptíveis espiraladas; cloroplastídios 25-30, discóides, parietais, ca. 4,8 $\mu \mathrm{m}$ diâm.; pirenóides nus presentes; grãos de paramido alongados, 2,0-6,0X1,0-1,3 $\mu \mathrm{m}$, dispersos no citoplasma; corpos mucíferos não observados; núcleo central, elíptico, ca. 15,0X8,0 $\mu \mathrm{m}$; estigma arredondado, granuloso, ca. 5,0 $\mu \mathrm{m}$ diâm.; flagelo 1/7-1/2 do comprimento da célula; metabolia acentuada, 
prendendo-se a partículas sólidas pelo pólo posterior, podendo permanecer imóvel por algum tempo; cistos e estádios palmelóides não observados.

Material examinado: R148124; R148125; R148136; R148137; R148138.

Distribuição geográfica no Estado do Rio de Janeiro: RIO DE JANEIRO: Manguinhos, Găvea (Cunha, 1913a, 1913b: 17); PARAÍBA DO SUL: local não especificado (Cunha, 1913a, 1913b: 17); RIO DE JANEIRO: Jardim Botânico do Rio de Janeiro (Kolkwitz, 1933: 400).

Pringsheim (1956) considera $E$. deses Ehr. uma espécie coletiva e, provavelmente, muitas das descrições existentes para suas expressões morfológicas estão sob outra denominação que não $E$. deses $\mathrm{Ehr}$. Tal fato, segundo este autor, justifica-se primeiro por não poder se estabelecer o tipo original descrito por Ehrenberg e segundo, pelo grau de variabilidade que esta espécie apresenta. Pringsheim (1956) propõe, então, que se tome arbitrariamente o grupo mais similar à diagnose original do tipo, dentre esse conjunto de espécies, para denominá-lo E. deses $\mathrm{Ehr}$.

Euglena deses Ehr., assim circunscrita, assemelha-se bastante a E. mutabilis Schmitz e a $E$. intermedia (Klebs) Schmitz, estas últimas também por nós encontradas no Estado do Rio de Janeiro. As diferenças entre elas são a ausência de pirenóides em $E$. intermedia (Klebs) Schmitz; e as células fusiformealongadas e os cloroplastídios maiores (ca. 5,0 um diâm.), com margens curvadas em direção ao periplasto em $E$. mutabilis $\mathrm{Schmitz}$.

Apesar de não ocorrerem com freqüencia na área em estudo, quando comparadas aos outros táxons do gênero, as três espécies foram encontradas em amostras populacionais de procedências distintas, o que nos facilitou uma delimitação sistemática mais precisa.

No material estudado proveniente do Rio de Janeiro, pudemos constatar variações semelhantes àquelas demonstradas por Pringsheim (1956) em seus clones, principalmente, quanto à evidenciação dos pirenóides, nem sempre de fácil visualização. Alguns dos exemplares analisados apresentaram tais estruturas bem nítidas, enquanto em outros os pirenóides só se tornaram visíveis na presença de hematoxilina de Heidenhain quando, então, adquiriram coloração amarelada. Conforme Pringsheim (1956), tais variações observadas em seus clones não são suficientes para constituir variedades, pois, para isto, deve-se cultivar a alga por maior tempo, sob condições estritamente controladas, estabelecendo-se, dessa forma, as diferenças hereditárias.

Em função disto e pelo fato de não termos trabalho com culturas, preferimos considerar, tal como Pringsheim (1956), tais variações como infra-específicas. 
Euglena ehrenbergii Klebs

Unters, bot. Inst. Tübingen 1: 304. 1883.

(Fig. 47-48)

Células cilíndricas, 114,5-174,0X12,6-21,7 $\mu \mathrm{m}(\overline{\mathrm{R}} \mathrm{c} / 1=8-9)$; pólo posterior sempre arredondado; periplasto com estrias finas, nítidas, espiraladas; cloroplastídios numerosos, lenticulares, parietais, 3,0-4,0X2,0 $\mu \mathrm{m}$; pirenóides ausentes; grãos de paramido numerosos, anulares, arredondados, ca. 1,0 $\mu \mathrm{m}$ diâm., outros alongados, ca. 1,3 X 0,7 $\mu \mathrm{m}$, dispostos irregularmente no citoplasma; corpos mucíferos fusiformes; vesículas de fosfolipídios, ca. 1,0 $\mu \mathrm{m}$ diâm., concentradas na regiẩo anterior do núcleo; núcleo no terço médio da célula, oblongo, ca. 23,0X10,0 $\mu \mathrm{m}$; estigma alongado, granuloso, ca. 5,8 X 3,6 $\mu \mathrm{m}$; flagelo ca. 1/6 do comprimento da célula; metabolia acentuada, com mudanças lentas na forma do corpo, principalmente na região anterior; cistos e estádios palmelóides não observados.

Material examinado: R147077; R147079; R147088; R148116; R148126; R148135.

Distribuição geográfica no Estado do Rio de Janeiro: RIO DE JANEIRO: Manguinhos (Cunha, 1913a, 1913b: 18).

Euglena ehrenbergii Klebs foi incluída por Pringsheim (1956) no subgênero Lentiferae, juntamente com $E$. proxima Dang. e $E$. variabilis Klebs nesse subgênero duvidoso, por esta apresentar forma de célula muito mais alongada que as outras Lentiferae e deslocamento semelhante ao de organismos do subgênero Serpentes, isto é, por reptação. Por outro lado, o referido autor acha-se incerto também na inclusão de E. ehrenbergii, Klebs em Serpentes uma vez não haver observado presença de pirenóides, característica esta muito importante na delimitação de ambos os subgêneros acima. Pringsheim (1956) sugere, então, que $E$. ehrenbergii Klebs provavelmente constitua um subgênero a parte de transição entre as Lentiferae e Serpentes, aproximando-se morfologicamente mais das primeiras.

Várias espécies consideradas distintas em literatura constituem, na realidade, sinonímias de $E$. ehrenbergii Klebs. Dentre elas, achamos que E . pringsheimii Skv. merece especial atenção, pelo fato de ter sido proposta a partir de material brasileiro, procedente do Estado de São Paulo. Em seu trabalho, Skvortzov (1967) propõe, para sua nova espécie, sete variedades que segundo ele, pertencem ao grupo de espécies de $E$. ehrenbergii Klebs, utilizando os seguintes critérios diferenciais: grãos de paramido granulares para $E$. pringsheimii Skv., nunca em bastōes alongados como em $E$. ehrenbergii Klebs; corpos mucíferos, hematocromo e vacúolos pulsáteis presentes na primeira e ausentes na segunda espécie.

Como Cardoso (1982), consideramos todos os táxons em Skvortzov (1967) idênticos a $E$. ehrenbergii Klebs, visto as características propostas pelo autor para $E$. pringsheimii Skv. ocorrem também em E. ehrenbergii Klebs. 
Além disto, a espécie de Skvortzov (1967) acha-se em desacordo com o Código Internacional de Nomenclatura Botânica (Stafleu et al., 1978), por já existir uma $\boldsymbol{E}$. pringsgheimii proposta por Iyengar (1962), efetiva e validamente publicada. Conseqüentemente, o epíteto proposto por Skvortzov (1967) tornase ilegítimo por estar previamente ocupado.

De acordo com o material estudado para o Rio de Janeiro, confirmamos as observações de Leedale (1967) e Cardoso (1982) de que a presença de grãos de paramido sob a forma de bastões alongados não é um caráter constante para $E$. ehrenbergii Klebs. Em nossas análises, nunca os encontramos sob esta forma, sendo que os grãos apresentaram-se com variação na forma desde anulares, arredondados, até alongados.

\section{Euglena gracilis Klebs}

Unters. bot. Inst. Tübingen 1: 303. 1883.

(Fig. 37-41)

Células basicamente fusiformes, 37,0-44,0X9,0-13,0 $\mu \mathrm{m}(\overline{\mathrm{R}} \mathrm{c} / 1=3,4-4)$; pólo posterior atenuado gradativamente em processo caudal cônico, hialino; periplasto com estrias finas, nítidas, espiraladas; cloroplastídios 8-10, discóides, parietais, de contorno irregular, ca. 6,0 $\mu \mathrm{m}$ diâm.; duplopirenóides presentes; grãos de paramido rumerosos, alongados, 1,5-2 X 0,7 $\mu \mathrm{m}$, dispersos no citoplasma; corpos mucíferos não observados; núcleo central, elíptico, ca. 5,0 X 3,5 $\mu \mathrm{m}$; estigma arredondado, granuloso, ca. 2,5 $\mu \mathrm{m}$ diâm.; flagelo quase do comprimento da célula; metabolia acentuada, célula com deslocamentos rápidos em zigue-zague; cistos e estádios palmelóides não observados.

Material examinado: R147071; R147074; R148136; R148138.

Distribuição geográfica no Estado do Rio de Janeiro: RIO DE JANEIRO: Manguinhos (Prowazek, 1910: 151); Baixada de Jacarepaguá, Lagoas Tijuca, Camorim e Jacarepaguá (Semeraro \& Costa, 1972: 14).

Apesar da diversidade registrada na literatura, E. gracilis Klebs foi uma espécie que nos causou grandes problemas quanto à sua identificação. Conforme Pringsheim (1956) as diferentes referências da literatura quanto à forma da célula e ao número, forma e arranjo dos cloroplastídios podem, possivelmente, ser explicadas pela variabilidade que esta espécie apresenta sob diferentes condições ambientais. Acrescenta, ainda, o autor, que muitas variedades de E. gracilis Klebs foram, sem dúvida, descritas, em sua maioria, tomando-se por base tais variaçōes.

Cardoso (1982) diz que E. gracilis Klebs é muito instável em suas características morfológicas, com pirenóides pouco visíveis e que pode, pelo seu deslocamento muito rápido, ser facilmente confundida com $E$. agilis H.J. Cart. e $E$. viridis Ehr. Pringsheim (1956) discute a grande semelhança morfológica de $E$. gracilis Klebs com $E$. clara Skuja elucidada por Skuja (1948) e por Gojdics (1953). Segundo Pringsheim (1956), esta semelhança não é tão grande assim, pois $E$. clara Skuja tem cloroplastídios lenticulares, com a concavidade 
voltada para o periplasto, margens irregulares lobadas, emitindo processos que correm paralelamente às estrias espiraladas do periplasto. Difere, ainda, E. clara Skuja de $E$. gracilis Klebs, pelo fato da primeira não crescer em meio de cultura puro com substâncias orgânicas.

O material estudado do Rio de Janeiro foi observado em amostra populacional junto a outras espécies de Euglena, não aparecendo com muita freqüência na região estudada. Este fato concorda com as afirmações em Pringsheim (1956) e Cardoso (1982), de que tal espécie ocorre freqüentemente em pequeno número, sempre entre outras espécies do.gênero. A análise dos nossos exemplares confirma parte da instabilidade morfológica da espécie observada na literatura consultada. $\mathrm{O}$ material coletado foi mantido vivo durante quinze dias em geladeira e, durante este período, efetuamos observações periódicas. Em noşso primeiro exame, três horas após a coleta, observamos indivíduos com células alongadas, tipicamente fusiformes, leve formação de processo caudal e cloroplastídios de coloração verde intensa, discóides, com margens levemente onduladas (Fig. 37). Em análises posteriores, constatamos células sub-cilíndricas, algumas vezes até mesmo obovadas, com processo caudal raramente perceptível, às vezes faltando, com cloroplastídios com lobos mais pronunciados e coloração mais clara (Fig. 38-41). Em nossas observações, alguns indivíduos mostraram-se totalmente acloróticos.

Não observamos, no entanto, alteração no número de cloroplastídios e nem, tampouco, os pirenóides apresentaram-se de difícil observação nas formas verdes. Pelo contrário, estes últimos mostraram-se sempre visíveis, com exceção óbvia dos exemplares apigmentados. Entretanto, como não efetuamos cultivo do material, não pudemos obter dados mais concretos quanto às variações citadas acima e nem, tampouco, informações mais objetivas do porque da suscetibilidade das alterações morfológicas e fisiológicas nesta espécie. A identificação de nossas algas com $E$. gracilis Klebs baseou-se nos caracteres morfológicos utilizados por Pringsheim (1956).

\section{Euglena granulata (Klebs) Schmitz}

Jb. wiss. Bot. 15: 16, 1884.

(Fig. 20-21)

BASIÔNIMO: Euglena velata Klebs var. granulata Klebs, Unters. bot. Inst. Tübingen 1: 301.1883.

Células basicamente fusiformes, 60,0-80,0X11,0-15,0 $\mu \mathrm{m}(\overline{\mathrm{R}} \mathrm{c} / 1=\mathrm{ca} .5,4)$; pólo posterior atenuado gradativamente em processo caudal cônico, hialino; periplasto com estrias finas, nítidas, espiraladas; cloroplastídios 10-12, discóides, parietais, margens onduladas levemente curvada para o periplasto, ca. 15,0 X $18,0 \mu \mathrm{m}$; duplopirenóides presentes; grãos de paramido numerosos, anulares, ca. 2,8 X 1,0 $\mu \mathrm{m}$, outros em forma de bastões, 3,5-4 X 2,4 $\mu \mathrm{m}$, dispersos no citoplasma; corpos mucíferos arredondados, refringentes, semelhantes a granulações sob o periplasto, distribuído entre as estrias; núcleo central, elíptico, ca. 
9,7 $\times$ 7,0 $\mu \mathrm{m}$; estigma alongado, granuloso, ca. 4,5 $\times 2,3 \mu \mathrm{m}$; flagelo ca. do comprimento da célula; metabolia pouco acentuada, nado lento, deslocamento em espiral; cistos e estádios palmelóides não observados.

Material examinado: R148126.

Distribuição geográfica no Estado do Rio de Janeiro: primeira citação da ocorrência da espécie.

Euglema granulata (Klebs) Schmitz é facilmente identificada pelo arranjo dos corpos mucíferos, bem desenvolvidos, entre as estrias do periplasto. Chu (1946) considera $E$. granulata (Klebs) Schmitz um forma de $E$. caudata Hübn. que se apresenta com corpos mucíferos relativamente mais desenvolvidos.

No material estudado do Rio de Janeiro, conseguimos identificar as duas espécies e, apesar do exame não ser efetuado em amostra populacional para ambas, observamos algumas diferenças entre elas, como segue: núcleo elíptico e 10 a 12 cloroplastídios em $E$. granulata (Klebs) Schmitz e núcleo arredondado e 20 a 25 cloroplastídios em $E$. caudata Hübn. Mesmo com exame de poucos indivíduos e com diferenças não muito grandes, consideramos as duas espécies independentes, até que se efetuem estudos mais concretos que nos permitam esclarecer melhor a delimitação desses táxons.

As algas identificadas para o Rio de Janeiro apresentaram características morfológicas próximas à descrição e a ilustração de Pringsheim (1956) para $E$. granulata (Klebs) Schmitz, com exceção das dimensões de largura da célula, que em nossas plantas foi de 11,0-15,0 $\mu \mathrm{m}$, média 13, inferiores às citadas pelo autor que variaram de $16,0-25,0 \mu \mathrm{m}$, média de 20,5 .

Euglena intermedia (Klebs) Schmitz

Jb. wiss. Bot. 15: 390. 1884.

(Fig. 35)

BASIÔNIMO: Euglena deses Ehr. var. intermedia Klebs, Unters. bot. Inst. Tübingen 1: 303, pl. 3, fig. 1. 1883.

Células cilíndricas, 138,0-203,0 X 12,0-16,0 $\mu \mathrm{m}(\overline{\mathrm{R}} \mathrm{c} / 1=15,8-18,8)$; pólo posterior atenuado abruptamente em processo caudal cilíndrico, hialino; periplasto com estrias finas, pouco perceptíveis, espiraladas; cloroplastídios 25-34, discóides, parietais, ca. 5,0 $\mu \mathrm{m}$ diâm.; pirenóides ausentes; grãos de paramido 6 , anulares, 10,0-20,0 $\times 3,8-5,0 \mu \mathrm{m}$, outros menores, alongados, 3,0 $\times 1,5-1,8$ $\mu \mathrm{m}$; corpos mucíferos arredondados, localizados nas regiões anteriores e posterior da célula; núcleo central, oblongo, ca. 25,0 X 6,8 $\mu \mathrm{m}$; estigma alongado, granuloso, ca. 6,0 $\mu \mathrm{m}$ compr.; flagelo ca. $1 / 7$ do comprimento da célula; metabolia restrita a torções da célula, com abaulamento da região anterior, deslocamento lento; cistos e estádios palmelóides não observados.

Material examinado: R148126.

Distribuição geográfica no Estado do Rio de Janeiro: primeira citação da ocorrência da espécie. 
Euglena intermedia (Klebs) Schmitz é uma espécie que apresenta inúmeras considerações quanto à sua posição taxonônica.

Klebs (1883) é o primeiro a descrevê-la e considerá-la uma variedade de $E$. deses Ehr. Lemmermann (1910) utiliza a ilustração original de Klebs para representar $E$. deses var. deses e, em 1913, o mesmo autor (Lemmermann, in Pascher, 1913) utiliza a ilustração de $E$. deses Ehr. var. intermedia Klebs para representar, desta vez, E. intermedia (Klebs) Schmitz, que considera, então, uma espécie independente, conforme proposição de Schmitz (1884). Pringsheim (1956) inclui $E$. intermedia (Klebs) Schmitz no subgênero Serpentes e demonstra dúvidas quanto à ausência de pirenóides como a principal característica em sua identificação. Por outro lado, Gojdics (1953) descreve e ilustra E. intermedia (Klebs) Schmitz sem pirenóides. Apesar de haver estudado uma única amostra, encontramos uma população bastante representativa de indivíduos e pudemos constatar que a ausência de pirenóides foi um caráter constante em todas as algas examinadas. Assim, não entendemos como válida a consideração de $E$. intermedia (Klebs) Schmitz como uma variedade de $E$. deses Ehr. pois esta última apresenta-se com pirenóides. Nosso posicionamento ao considerar os dois táxons independentes foi reforçado pela identificação de E. deses Ehr. também em material do Rio de Janeiro.

Para melhor esclarecimento, segue a tabela comparativa entre as duas espécies com base no material da área em estudo:

\begin{tabular}{lccl}
\hline & $\begin{array}{c}\text { Dimensões da } \\
\text { célula }\end{array}$ & $\overline{\mathrm{R}} \mathrm{c} / 1$ & Pirenóides \\
\hline E. intermedia & $\begin{array}{l}188,0-203,0 \mathrm{X} \\
12,0-16,0 \mu \mathrm{m}\end{array}$ & $15,8-18,8$ & ausentes \\
& $\begin{array}{l}\text { 109,0-130,0 X } \\
\text { E. deses }\end{array}$ & $8,6-9,1$ & presentes \\
& $12,0-15,0 \mu \mathrm{m}$ & & \\
\hline
\end{tabular}

Entendemos que, além dos pirenóides, característica realmente distintiva entre as duas espécies, as dimensões e a razão média comprimento/largura celulares, apresentam-se como critérios auxiliares na delimitação de ambas. Provavelmente, $E$. intermedia (Klebs) Schmitz forma um subgênero à parte, próximo à $E$. ehrenbergii Klebs, ainda que apresente morfologia semelhante à de representantes do subgênero Rigidae, com exceção da metabolia que, neste subgênero, não é acentuada, como em $E$. intermedia (Klebs) Schmitz. Nossos resultados da identificação apresentam-se próximos aos de Gojdics (1953) para E. intermedia (Klebs) Schmitz com exceção as dimensões Rc/1 celulares que, segundo a autora, são de 93,0-124,0 X 9,3-12,4 $\mu \mathrm{m}(\overline{\mathrm{R}} \mathrm{c} / 1=10)$, portanto inferiores às das nossas plantas. Conforme Palmer (1969), E. intermedia (Klebs) 
Schmitz é tolerante à poluição orgânica aquática, tendo sido citada por 11 autores, com um total de 12 pontos, o que concordou com o local procedente de nossa amostra R148126, que se apresentou com boa quantidade de materia orgânica.

\section{Euglena limmophila Lemm.}

Beih. bot. Zbl. 76(44-45): 152. 1898.

(Fig. 13-14)

Células fusiformes, 50,6-64,6X9,2-11,5 $\mu \mathrm{m}(\overline{\mathrm{R}} \mathrm{c} / 1=5,5-5,6)$; pólo posterior atenuado gradativamente em processo caudal cônico, hialino; periplasto com estrias finais, pouco nítidas, espiraladas, algumas vezes ausentes; cloroplastídios numerosos, discóides, parietais, 3,5-5,0 $\mu \mathrm{m}$ diâm.; pirenóides ausentes; grãos de paramido 2, em forma de bastões, um anterior e outro posterior ao núcleo, ca. 11,0 X 4,8 $\mu \mathrm{m}$; corpos mucíferos não observados; núcleo central, elíptico, ca. 12,0 X 5,0 $\mu \mathrm{m}$; estigma arredondado, compacto, ca. 5,0 $\mu \mathrm{m}$ diâm.; flagelo ca. 1/3 do comprimento da célula; metabolia restrita a algumas torções da célula; cistos e estádios palmelóides não observados.

Material examinado: R147068; R147070; R147075.

Distribuição geográfica no Estado do Rio de Janeiro: primeira citação da ocorrência da espécie.

Euglena limnophila Lemm. apresenta sua morfologia muito próxima à de $E$. acus Ehr. e E. megalithos Skuja. Euglena limnophila Lemm. difere de $E$. acus Ehr. pelas dimensões e $\bar{R} c / 1$ celulares: enquanto a primeira apresenta dimensões de 50,6-64,4 X 9,2-11,5 $\mu \mathrm{m}$ e $\overline{\mathrm{R}} \mathrm{c} / 1$ de 5,5-5,6, a segunda mede 124,0-165,0 X 11,5-14 $\mu \mathrm{m}$ com Rc/1 de 9,62-11,8. Distinguimos E. limnophila Lemm. de $E$. megalithos Skuja pelas maiores dimensões dos cloroplastídios (ca. $10,0 \mu \mathrm{m}$ diâm.) e dos grãos de paramido (ca. 28,0 X 7,0 $\mu \mathrm{m}$ ) em E. megalithos Skuja, enquanto que $E$. limnophila Lemm. apresenta-os com 3,0-5,0 $\mu \mathrm{m}$ e ca. $11,0 \times 4,8 \mu \mathrm{m}$, respectivamente. O material examinado do Rio de Janeiro apresentou-se de acordo com os caracteres morfológicos descritos e ilustrados por Pringsheim (1956) para E. limnophila Lemm.

\section{Euglena mutabilis Schmitz var. mutabilis}

Jb. wiss. Bot. 15: 37, pl. 1, fig. 3, 1884.

(Fig. 28-29)

Células estreitamente fusiformes, às vezes cilíndricas na região mediana, $100,0-136,0 \times 8,0-11,0 \mu \mathrm{m}(\overline{\mathrm{R}} \mathrm{c} / 1=12,3-12,5)$; pólo posterior atenuado gradativamente em processo caudal cilíndrico, periplasto com estrias finas, nítidas espiraladas; cloroplastídios 8-10, discóides, parietais, margens curvadas para o periplasto, 5,0-10,0 $\mu \mathrm{m}$ diâm; pirenóides nus presentes; grãos de paramido numerosos, oblongos, ca. 3,5 X 2,0 $\mu \mathrm{m}$, outros menores, alongados, ca. 2,8 $\mu \mathrm{m}$ compr.; corpos mucíferos arredondados, distribuídos irregularmente no cito- 
plasma; núcleo central, oblongo, ca. 12,4 X 6,8 $\mu \mathrm{m}$; estigma arredondado, granuloso, ca. 3,0 $\mu \mathrm{m}$ diâmetro; flagelo não observado; metabolia acentuada, prendendo-se ao substrato pelo pólo posterior, com giros e encurtamentos na parte anterior, deformações acentuadas na parte mediana da célula; cistos e estádios palmelóides não observados.

Material examinado: R147098; R148140.

Distribuição geográfica no Estado do Rio de Janeiro: primeira citação da ocorrência da espécie tipo.

Segundo Pringsheim (1956), E. mutabilis Schmitz pode ser facilmente separada das demais espécies do subgênero Serpentes pela raridade do flagelo.

Apesar das nossas observações terem confirmado as de Pringsheim (1956), quanto à raridade do flagelo, achamos que tal critério para a identificação sistemática da espécie pode falhar, pois nem sempre tal estrutura é de fácil observação. Outros táxons desse subgênero identificados também para o Rio de Janeiro foram $E$. deses Ehr. e $E$. intermedia (Klebs) Schmitz que, podem em exame superficial, ser facilmente confundidos com E. mutabilis Schmitz, em função do alto grau de metabolia que estas espécies apresentam, dificultando bastante sua diferenciação imediata. Euglena intermedia (Klebs) Schmitz difere, entretanto, de ambas pela ausência de pirenóides, enquanto que os critérios diferenciais entre $E$. deses Ehr. e $E$. mutabilis Schmitz seguem na tabela abaixo:

\begin{tabular}{lccccc}
\hline & $\begin{array}{c}\text { Forma da } \\
\text { célula }\end{array}$ & $\begin{array}{c}\text { Pólo } \\
\text { posterior }\end{array}$ & $\begin{array}{c}\text { No e forma dos } \\
\text { cloroplastídios }\end{array}$ & Flagelo & Núcleo \\
\hline E. deses & cilíndrica & $\begin{array}{c}\text { atenuado } \\
\text { abruptamente }\end{array}$ & $\begin{array}{c}25-30 \\
\text { margens não } \\
\text { curvadas }\end{array}$ & presente & elíptico \\
$\begin{array}{l}\text { E. } \\
\text { mutabilis }\end{array}$ & fusiforme gradativamente & $\begin{array}{c}\text { 8 a 10 } \\
\text { margens } \\
\text { curvadas }\end{array}$ & ausente & oblongo \\
\hline
\end{tabular}

De acordo com o exposto, as principais características para identificação de $E$. mutabilis Schmitz são o número reduzido de cloroplastídios, com margens curvadas para o periplasto e a célula fusiforme, com pólo posterior atenuado gradativamente, sendo o demais aspectos morfológicos apenas auxiliares na sua identificação. Gojdics (1953) e Cardoso (1982) citam a oorrência de granulações citoplasmáticas em E. mutabilis Schmitz que, talvez, sejam os corpos mucíferos observados por nós em nosso material, que se coraram vivamente na presença de vermelho-neutro. Todos os exemplares analisados para o Rio de 
Janeiro apresentaram-se com características constantes, que se aproximaram àquelas citadas por Pringsheim (1956) para E. mutabilis Schmitz var. mutabilis.

Euglena oxyuris Schmarda var. charkowiensis (Swir.) Chu Sinensia 17(1,6): 95.1946.

(Fig. 1-3)

BASIÔNIMO: Euglena charkowiensis Swir., Trav. Soc. nat. Univ. Imp. Kjarkow 64: 74, pl. 1, fig. 21. 1913.

Células cilíndricas, raramente torcidas, 130,0-155,0 X 20,0-29,0 $\mu \mathrm{m}$ $\overline{\mathrm{R}} \mathrm{c} / 1=5,3-6,5)$; pólo posterior atenuado abruptamente em processo caudal cônico, hialino, periplasto com estrias finas, nítidas, espiraladas; cloropastídios numerosos, discóides, parietais, ca. 3,0 $\mu \mathrm{m}$ diâm., pirenóides ausentes; grãos de paramido 2, anulares, 17,0-20,0 X 10,0 $\mu \mathrm{m}$, um anterior e outro posterior ao núcleo; corpos mucíferos não observados; núcleo central, oblongo, ca. 20,0 X $10,0 \mu \mathrm{m}$; estigma alongado, granuloso, ca. 9,0 $\times 2,8 \mu \mathrm{m}$; flagelo ca. $1 / 2$ do comprimento da célula; metabolia restrita a torções da célula, deslocamento em especial; cistos e estádios palmelóides não observados.

Material examinado: R147069; R147074; R147080; R148126; R148128; R148140.

Distribuição geográfica no Estado do Rio de Janeiro: primeira citação da ocorrência da variedade.

Euglena oxyuris Schmarda apresenta-se muito confusa quanto às dimensões celulares na literatura. A maioria dessas informações não faz menção à variedade típica da espécie, tornando-se, pois, difícil determiná-la, uma veż que as medidas citadas para a variedade típica, não raro interpolam-se àquelas das outras variedades propostas para $E$. oxyuris Schmarda. A confusão existente quanto às dimensões de $E$. oxyuris Schmarda e de suas variedades pode ser constatada nas tabelas que se seguem:

E. oxyuris Schmarda:

Célula

\begin{tabular}{lccc} 
Autores & Comprimento & Largura & $\overline{\mathrm{R}} \mathrm{c} / 1$ \\
\hline Schmarda (1846) & $180,0 \mu \mathrm{m}$ & $48,0 \mu \mathrm{m}$ & 3,73 \\
Lemmermann (1910) & $375,0-490,0 \mu \mathrm{m}$ & $30,0-44,0 \mu \mathrm{m}$ & $11-12,5$ \\
Dangeard (1901) & $490,0 \mu \mathrm{m}$ & $30,0-40,0 \mu \mathrm{m}$ & $12,3-16,3$ \\
Skuja (1948) & $136,0-190,0 \mu \mathrm{m}$ & $17,0-23,0 \mu \mathrm{m}$ & $8-8,2$ \\
Cardoso (1982) & $200,0-236,4 \mu \mathrm{m}$ & $24,0-32,0 \mu \mathrm{m}$ & $8,3-8,95$ \\
\hline
\end{tabular}


E. oxyuris Schmarda var. oxyuris:

Célula

\begin{tabular}{lccc} 
Autores & Comprimento & Largura & $\overline{\mathrm{R} c / 1}$ \\
\hline Swirenko (1915) & $352,0-378,0 \mu \mathrm{m}$ & $30,0-41,0 \mu \mathrm{m}$ & $9,2-11,7$ \\
Playfair (1921) & $250,0-400,0 \mu \mathrm{m}$ & $22,0-46,0 \mu \mathrm{m}$ & $8,9-11,3$ \\
$\begin{array}{l}\text { Deflandre (1928) } \\
\text { Gojdics (1953) }\end{array}$ & $302,0 \mu \mathrm{m}$ & $25,0 \mu \mathrm{m}$ & 12 \\
$\begin{array}{l}\text { Huber-Pestalozzi } \\
\text { (1955) }\end{array}$ & $371,0-339,0 \mu \mathrm{m}$ & $19,0-40,0 \mu \mathrm{m}$ & $8,45-11,1$ \\
& & & \\
\hline
\end{tabular}

E. oxyuris Schmarda var. minor Def.:

Célula

\begin{tabular}{lccc} 
Autores & Comprimento & Largura & $\bar{R} c / 1$ \\
\hline Playfair (1921) & $156,0-250,0 \mu \mathrm{m}$ & $20,0-22,0 \mu \mathrm{m}$ & $7,8-11,3$ \\
Deflandre (1924b) & $170,0-190,0 \mu \mathrm{m}$ & $23,0 \mu \mathrm{m}$ & $7,3-8,2$
\end{tabular}

E. oxyuris Schmarda var. minor Presc.:

\begin{tabular}{llll}
\hline Autor & Comprimento & $\begin{array}{c}\text { Célula } \\
\text { Largura }\end{array}$ & $\overline{\mathrm{R}} \mathrm{c} / 1$ \\
\hline Prescott (1944) & $74,0-86,0 \mu \mathrm{m}$ & $6,5-10,0 \mu \mathrm{m}$ & $4,7-5,1$ \\
\hline
\end{tabular}

E. oxyuris Schmarda var. gracilima Playf.:

\begin{tabular}{lccc}
\hline Autor & Comprimento & $\begin{array}{c}\text { Célula } \\
\text { Largura }\end{array}$ & $\overline{\mathrm{R}} \mathrm{c} / 1$ \\
\hline Playfair (1921) & $253,0 \mu \mathrm{m}$ & $17,0 \mu \mathrm{m}$ & 19,4 \\
\hline
\end{tabular}

Borrelly (1949), ao estudar três amostras populacionais de E. oxyuris Schmarda procedentes de quatro regiōes da França, delimita quatro variedades, baseado, exclusivamente, nas diferentes dimensões observadas por ele e citadas em literatura. Em suas observações, esse autor conclui que as variações da forma da célula, do volume dos grãos de paramido, número de quilhas e de estriações correspondiam, diretamente, às diferenças nas dimensões celulares. Propõe, então, que E. charkowiensis Swir., E. charkowiensis Swir. var. minor 
Skv., E. gigas Drez., E. estonica Möld. e $E$. allorgei Def. sejam reunidas a $E$. axyuris Schamarda, por aquelas diferirem desta somente pelas dimensões tratando-se, pois, mais provavelmente, de expressões morfológicas de um mesmo táxon.

As variedades propostas por Bourrelly (1949) foram as seguintes:

E. oxyuris Schmarda var. minima Bourr. (é a var. minor Presc.); dimensões: $74,0-86,0 \times 6,5-10,0 \mu \mathrm{m}(\overline{\mathrm{R}} \mathrm{c} / 1=7,6-12,6)$

E. oxyuris Schmarda var. charkowiensis (Swir.) Chu (e E. charkowiensis Swir); dimensões: $125,0-150,0 \times 20,0-27,0 \mu \mathrm{m}(\overline{\mathrm{R}} \mathrm{c} / 1=5-6,2)$

$E$. oxyuris Schmarda var. estonica (Möld.) Bourr. (é E. estonica Möld.); dimensōes: $195,0-231,0 \times 17,5-27,0 \mu \mathrm{m}(\overline{\mathrm{R}} \mathrm{c} / 1=4,5-6,7)$

E. oxyuris Schmarda var. playfairi Def. (é E. oxyuris Schmarda var. gracilima Playf.); dimensões: 247,0-290,0 X 20,0-30,0 $\mu \mathrm{m}(\overline{\mathrm{R}} \mathrm{c} / 1=9,30-11,2)$

O trabalho de Bourrelly (1949) vem reforçar a necessidade de se estudar melhor os critérios utilizados na delimitação dos táxons infra-específicos de $E$. oxyuris Schmarda. É provável que algumas das dimensões citadas na literatura correspondam, verdadeiramente, à variedade de $E$. oxyuris Schmarda. Entretanto, achamos melhor considerar as dimensões propostas originalmente por Schmarda (1846) para E. oxyuris Schmarda var. oxyuris, apenas por serem as originais. Apesar de $E$. oxyuris apresentar morfologia próxima a $E$. tripteris (Duj.) Klebs, podemos distinguí-las pela secção transversal elíptica na primeira e trirradiada na segunda. Os indivíduos analisados do Rio de Janeiro mostraram-se com dimensões superiores às de Schmarda para $E$. oxyuris Schmarda var. oxyuris. Ainda que não tivessemos considerado tais medidas para a variedade típica da espécie, nosso material apresentou-as inferiores quando comparados àquelas citadas na literatura, aproximando-se muito do intervalo proposto por Bourrelly (1949) para E. oxyuris Schmarda var. charkowiensis (Swir.) Chu, sendo por isso, identificado como tal.

Euglena spirogyra Ehr. var. spirogyra

Infus. 110, pl. 7, fig. 10. 1838.

(Fig. 17-19)

Células cilíndricas, às vezes torcidas, 82.4-128.0 X 9.2-15.5 $\mu \mathrm{m}$ $(\overline{\mathrm{R}} \mathrm{c} / 1=8,2-9)$; pólo posterior atenuado abruptamente em processo caudal cônico, hialino; periplasto castanho-claro, com estrias finas, nítidas, espiraladas, com pequenas verrugas esféricas entre as estrias, variando em número e grau de desenvolvimento; cloroplastídios numerosos, discóides, parietais, 3,0-4,0 $\mu \mathrm{m}$ diâm.; pirenóides ausentes, grãos de paramido 2, anulares, alongados, um anterior e outro posterior ao núcleo, 10,0-15,0 X 5,0-7,0 $\mu \mathrm{m}$; outros menores, alongados, 1,0-1,5 $\mu \mathrm{m}$ compr., dispersos no citoplasma; corpos mucíferos não observados; núcleo central; esférico, ca. 10,0 $\mu \mathrm{m}$ diâm.; estigma arredondado. granuloso, 2,0-2,5 $\mu \mathrm{m}$ diâm.; flagelo ca. $1 / 3$ do comprimento da célula; cistos e estádios palmelóides não observados. 
Material examinado: R147099; R148120.

Distribuição geográfica no Estado do Rio de Janeiro: primeira citação da ocorrência da espécie tipo.

Euglena spirogyra Ehr. é uma espécie muito confusa e observam-se, na literatura especializada. descrições e ilustrações variáveis quanto às dimensões e à razão média comprimento/largura da célula. à quantidade de grãos de paramido e ao tamanho do flagelo.

Ehrenberg (1838) cita. na descrição original da espécie, dimensōes entre $112,0-125,0 \mu \mathrm{m}$ de comprimento, aspecto granular do periplasto e flagelo tão longo quanto a célula. Perty (1852) e Stein (1878) descrevem e ilustram essa espécie com excesso de reserva nutritiva (10 a 17 grãos de paramido em forma de bastões) que Pringsheim (1956) considera como formas anômalas. Lemmermann. in Pascher (1913). Lefèvre (1934) e Johnson (1944) descrevem o flagelo de E. spirogyra Ehr. como muito curto, enquanto Pritchard.(1852) e Dangeard (1901) descrevem-no como quase do comprimento da célula ou até um pouco mais longo. Pringsheim (1956) comenta que a feição mais adequada para caracterizar as variedades agrupadas nesta espécie é a presença de verrugas e considera que as diferentes dimensões de tamanho da célula estão relacionadas apenas com a diferença do número cromossômico.

Entre as variedades propostas para E. spirogyra Ehr., consideramos somente as variedades minor All. \& Lef. e fusca Klebs, esta última também encontrada em material do Rio de Janeiro. A var. minor All. \& Lef. é aceita por bom número de autores (Gojdics, 1953; Pringsheim, 1956; Cardoso, 1982) e apresenta dimensões que variam entre 45,0-30,0 X 7,0-9,0 $\mu \mathrm{m}(\overline{\mathrm{R}} \mathrm{c} / 1=5,5-6,4)$, isto $\hat{\epsilon}$, um intervalo muito inferior e bastante significativo quando comparado ao da variedade típica da espécie, que apresenta dimensões entre 82,3-128,0 X $9,2-15,5 \mu \mathrm{m}(\overline{\mathrm{R}} \mathrm{c} / 1=8,2-9)$. Quanto à var. fusca $\mathrm{Klebs,}$ esta apresenta ornamentação do periplasto muito mais complexa que em E. spirogyra Ehr. var. spirogyra.

Quanto às outras variedades, tais como abrupte-acuminata (Hübn.) Lemm., suprema Skuja, elegans Playf., marchica Lemm. e laticlavius Lemm., achamos que merecem criteriosa revisão por estarem calcadas, basicamente, no arranjo, na quantidade e no grau de desenvolvimento das verrugas, caracteres estes que nos parecem frágeis na delimitação desses táxons.

No material analisado do Rio de Janeiro, observamos que, em uma mesma amostra, nem todos os indivíduos apresentaram-se com a mesma quantidade e o mesmo grau de desenvolvimento das verrugas, o que nos leva a supor que se trate de diferentes estádios de desenvolvimento da planta. A identificação das algas que observamos aproxima-se bastante da descrição e das ilustrações de Pringsheim (1956) para E. spirogyra Ehr. var. spirogyra, exceção feita à forma do núcleo que, no nosso caso, apresentou-se esférico e não elíptico como citado pelo referido autor. 
Euglena spirogra Ehr. var. fusca Klebs

Unters. bot. Inst. Tübingen 1: 77. 1883.

(Fig. 15-16)

Difere da variedade típica da espécie pelas maiores dimensões da célula, atenuada na região posterior, $184,0-252,0 \times 22,0-26,0-\mu \mathrm{m}(\overline{\mathrm{R}} \mathrm{c} / 1=8,4-9,7)$, dos cloroplastídios, 5,0-6,0 $\mu \mathrm{m}$ diâm.; dos grãos de paramido, ca. 40,0 X 12,0 $\mu \mathrm{m}$, do estigma, 5,0-7,8 $\mu \mathrm{m}$ diâm.; pelo núcleo elíptico e pela presença de verrugas poligonais, mais desenvolvidas, conferindo coloração mais intensa ao periplasto.

Material examinado: R147106; R148119; R148120.

Distribuição geográfica no Estado do Rio de Janeiro: RIO DE JANEIRO: Manguinhos (Cunha, 1913a, 1913b: 18, como Euglena fusca (Klebs) Lemm.)

Klebs (1883), ao descrever E. spirogyra Ehr. var. fusca Klebs, difere-a de E. spirogyra Ehr. var. spirogyra por suas maiores dimensões celulares, pelo flagelo mais longo e pela coloração mais intensa do periplasto. Lemmermann, in Pascher (1913) considera a var. fusca Klebs independente de $E$. spirogyra Ehr. e eleva-a à categoria de espécie, $E$. fusca (Klebs) Lenım., justiticando sua decisão pelo comprimento do flagelo que, segundo apresenta-se mais longo em E. spirogyra Ehr. Lefévre aceita a mudança efetuada por Lemmermann (1913) e acrescenta que, além do maior comprimento do flagelo, E. fusca (Klebs) Lemm. apresenta ornamentação mais complexa que em $E$. spirogyra $\mathrm{Ehr}$. O autor descreve a ornamentação de $E$. fusca com verrugas bem desenvolvidas, poligonais, sendo que na base do processo caudal, tais verrugas se apresentam triangulares.

Pringsheim (1956) concorda com Klebs (1883) e Lefévre (1934) quanto à caracterização do periplasto desta variedade e sugere que seja assim conservada conforme a proposição original de Klebs.

Cardoso (1982) comenta a dificuldade de se estabelecer, com precisão, os reais limites métricos de $E$. spirogyra Ehr., que se apresenta com diferentes graus de torções da célula, o que dificulta a separação de seus táxons infra-específicos. Acrescenta, ainda, que apesar do flagelo mais comprido na var. fusca Klebs, este é um caráter frágil para sua delimitação, visto ser caduciforme neste grupo e de rápido crescimento.

Nas coletas efetuadas no Rio de Janeiro, conseguimos identificar tanto $E$. spirogyra Ehr. var. spirogyra como $E$. spirogyra Ehr. var. fusca Klebs, cujas diferenças seguem na tabela.

\begin{tabular}{lccl}
\hline & $\begin{array}{c}\text { Dimensões } \\
\text { celulares }\end{array}$ & $\overline{\mathrm{R}} \mathrm{c} / 1$ & Periplasto \\
\hline $\begin{array}{l}\text { E. spirogyra } \text { var. } \\
\text { spirogyra }\end{array}$ & $\begin{array}{c}82,4-128,0 \mathrm{X} \\
9,2-15,5 \mu \mathrm{m}\end{array}$ & $8,2 \mathrm{a}$ & verrugas \\
esféricas
\end{tabular}



E. spirogyra var.
$184,0-252,0 \mathrm{X}$
8,4 a
fusca
$22,0-26,0 \mu \mathrm{m}$
9,7
verrugas
poligonais

Observamos, então, que a principal característica distintiva entre os dois táxons é o tipo de ornamentação, que na var. fusca apresenta-se com verrugas mais desenvolvidas, quadradas, retangulares próximas à região anterior da célula, triangulares, trapezoidais na região mediana. sendo que no terço médio posterior da célula tornam-se mais angulares, alongando-se no pólo posterior.

Apesar das maiores dimensões de E. spirogyra Ehr. var. fusca Klebs. não encontramos um intervalo de diferença muito significativo quanto à $\bar{R} c / 1$ entre as duas variedades. Tampouco achamos que, as maiores dimensões dos cloroplastídios. dos grãos de paramido e do estigma da var. fusca Klebs, sejam primordiais na sua delimitação. pois nada impede que as maiores dimensões dessas estruturas estejam relacionadas às maiores dimensões celulares.

\section{Euglena splendens Dang}

Botaniste 8: 69, fig. 9. 1901.

(Fig. 22-27)

Células amplamente fusiformes, 79.0-92.0 X $15.0-27.0 \quad \mu \mathrm{m}$ $(\overline{\mathrm{R}} \mathrm{c} / 1=3.4-5.3)$; pólo posterior atenuado gradativamente em processo caudal cônico. hialino; periplasto com estrias finas, pouco perceptíveis, espiraladas; cloroplastídios numerosos, franjados, com as projeções irradiadas para a periferia da célula. semelhantes a fitas estreitas, anastomosadas, dispostas em espiral. quando em vista frontal; duplopirenóides presentes; grãos de paramido numerosos, arredondados, ca. 6,0 $\mu \mathrm{m}$ diâm., concentrados principalmente na região mediana da célula; corpos mucíferos arredondados, dispostos entre os cloroplastídios no plano subsuperficial da célula; núcleo central, amplamente elíptico. ca. $12.0 \times 7,8 \mu \mathrm{m}$; estigma alongado, granuloso. ca. $4.0 \times 2.5 \mu \mathrm{m}$; flagelo 1.5-2 vezes o comprimento da célula; metabolia pouco acentuada, deslocamento em torno do próprio eixo da célula; cistos com envoltório mucilaginoso firme. fino, algumas vezes com um segundo envoltório, copioso. hialino.

Material examinado R148124; R148133.

Distribuição geográfica no Estado do Rio de Janeiro: primeira citação da ocorrência da espécie.

Euglena splendens Dang. foi uma espécie de difícil identificação, pois pertence a um grupo de táxons muito próximos entre si (e que apresentam um complexo sistema cloroplastídio-pirenóide) representado, de acordo com Pringsheim (1956), por E. sanguinea Ehr., E. oblonga Schmitz, E. magnifica Prings. e $E$. laciniata Prings.

Estas espécies não estão bem delimitadas. confundindo-se muito, e suas descrições existentes na literatura consultada divergem extremamente na caracterização dos cloroplastídios, na presença dos pirenóides e na forma dos corpos mucíferos. 
Chu (1946) é o primeiro a descrever e ilustrar, de forma mais adequada, o sistema plastidial desse grupo de espécies e refere-se, também. pela primeira vez, à presença de pirenóides. Assim, representa $E$. sanguinea Ehr. com numerosos cloroplastídios estrelados. com projeções irradiadas do centro para a periferia da célula. assemelhando-se a cloroplastídios distintos arranjados em espiral e paralelo às estrias do periplasto. Cada cloroplastídio porta uma bainha de pirenóide e as fitas componentes dos cloroplastídios podem ramificar-se. unindo-se umas às outras pelos seus extremos assumindo, assim. aspecto de retículo. Skuja (1948) comenta a dificuldade de observação dos pirenóides nessas espécies. Segundo esse autor. os pirenóides provavelmente representem o verdadeiro ponto de partida dos cloroplastídios estrelados. apesar de nem sempre serem bem desenvolvidos e acarretar. com isso. sua má visualização. Além disto. a região que os pirenóides ocupam na célula está preenchida por numerosos grãos de paramido. mascarando-os quase que totalmente. Os comentários de Skuja (1948) talvez justifiquem as descrições de $E$. splendens Dang.. que não referem a presença de pirenóides. Mignot (1967), ao estudar E. splendens Dang. em microscopia óptica e eletrônica. representa sua estrutura plastidial em vista frontal como um complexo labirinto de fitas anastomosadas, orientadas em diversas direções ao longo do periplasto. sendo a zona mais clara da região central preenchida por numerosos grãos de paramido. Mignot (1967) confirma a existência de numerosas fitas plastidiais irradiadas para a periferia da célula. bem como que os quatro grupos de fitas por ele observadas portam um duplopirenóide cada. Esse autor levanta, ainda. a possibilidade da existência de um número maior de pirenóides. visto estas estruturas nem sempre apresentarem-se distintas.

Pringsheim (1956) tenta estabelecer. em seus comentários à cerca destas espécies suas diferenças por obtenção de clones. Seus resultados e conclusões. entretanto. não se acham muito claros e, em alguns aspectos. tornam-se controvertidos. De acordo com o autor, E. sanguinea Ehr., E. oblonga Schmitz e E. splendens Dang. formam o subgênero Catilliferae. cuja característica primordial é a presença de cloroplastídios com duplopirenóides. Alegando descriçōes insuficientes e duvidosas de $E$. splendens Dang.. o autor faz uma nova descrição da espécie caracterizando-a pela ausência de pirenóides e hematocromo e pela presença de um grão de paramido isolado, próximo ao estigma. Apesar da não referência dos pirenóides em sua descrição, Pringsheim (1956) não exclui $E$. splendens Dang. das Catilliferae. Cria, ainda duas espécies: E. magnifica Prings e E. laciniata Prings., e difere-as das demais pelas menores dimensões. ausência de hematocromo, número de pirenóides. sendo que, para nós a descrição de $E$. laciniata Prings. aproxima-se muito da descrição de Skuja (1948) para E. splendens Dang.

Cardoso (1982) identifica. em estudo das Euglenaceae pigmentadas do Distrito Federal. três dessas espécies problemáticas, quais sejam: $E$. inagnifica Prings.. E. sanguinea Ehr. e E. laciniata Prings. Em seus comentários. a refe- 
rida autora diz que. entre os taxóns das Catilliferae, E. sanguinea Ehr. é a mais fácil identificação pela presença de hematocromo. seguida de $E$. laciniata Prings.. pelo reduzido número (6) de pirenóides de grandes dimensões. As demais espécies. E. splendens Dang.. E. oblonga Schmitz e E. magnifica Prings.. apresentam-se com sérios problemas de identificação.

Goidics (1953) utiliza. como critério diferencial entre $E$. oblonga Schmitz e $E$. splendens Dang.. a forma dos corpos mucíferos: globulosos na primeira e fusiformes na segunda.

O material estudado do Rio de Janeiro procede de duas amostras populacionais distintas. A quantidade de fitas plastidiais e sua coloração verde intensa dificultou-nos muito a observação da estrutura do sistema plastidial, bem como a grande quantidade dos grãos de paramido que mascaravam os pirenóides. Tạis estruturas só puderam ser evidenciadas com maior nitidez depois de certo tempo da amostra coletada ou quanto deparamos com organismos de forma esférica, podendo. então. confirmar os dados morfológicos citados por Chu (1946), Skuja (1948), Mignot (1967) para os cloroplastídios e pirenóides. Utilizamos, ainda. para melhor evidenciação dos pirenóides hematoxilina de Heidenhaim. Entretanto, a célula tornou-se extremamente sensível ao corante e deformou-se muito. apresentando algumas manchas amareladas, que. possivelmente, corresponderiam às regiōes dos pirenóides. Observamos. ao todo, seis pirenóides e em nenhum romento constatamos a presença do grãos de paramido isolado. próximo ao estigma, que Pringsheim (1956) utiliza como uma das características diacríticas de $E$. splendens Dang.

Nossas plantas poderiam ser identificadas comc $E$. laciniata Prings., apesar ds dimensōes encontradas serem pouco superiores àquelas citadas por Pringsheim (1956). que são de 65.0-72.0 X 17.0-20.0 $\mu \mathrm{m}(\overline{\mathrm{R}} \mathrm{c} / 1=3,6-3.8) \mathrm{ou}$, então. com $E$. oblonga Schmitz. apesar desta apresentar número de pirenóides superior ao dos organismos analisados por nós.

Achamos, entretanto, que as características citadas como diferenciais para estas espécies. tais como hematocromo. número de pirenóides e forma dos corpos mucíferos. possivelmente variam sob condições ambiemtais. Tampouco. encontramos em nossas coletas espécimes que pudessem. realmente. ser identificadas com $E$. sanguinea Ehr. e E. magnifica Prings. para que se efetuasse melhor comparação morfológica.

Frente a esses problemas. decidimos identificar nosso material com E.splendens Dang., considerando-se que os dados morfológicos citados por Chu (1946). Skuja (1948) e Mignot (1967) parecerem-nos bem definidos e aproximaram-se mais de nossos resultados.

Este fatos demonstram. mais uma vez. a necessidade de uma revisão crítica dos caracteres utilizados na delimitação das espécies e. conseqüentemente. do subgênero. 
Euglena tripteris (Duj.)Klebs

Unters. bot. Inst. Tübingen 1: 306. 1883.

(Fig. 9-12)

BASIÔNIMO: Phacus tripteris Duj., Hist. nat. Zoophytes

1841: 338, pl. 5. fig. 7. 1841.

Células cilíndricas, torcidas, trirradiadas em secção transversal, 70,0-90,00 X 11,5-13,0 $\mu \mathrm{m}(\overline{\mathrm{R}} \mathrm{c} / 1=6,1-5,0)$; pólo posterior atenuado gradativamente em processo caudal cônico. hialino, reto ou curvo; periplasto com estrias finas. nítidas, seguindo as torções da célula: cloroplastídios numerosos, discóides, parietais, ca. 3,0 $\mu \mathrm{m}$ diâm.. pirenóides ausentes; grãos de paramido 2 , em forma de bastōes. anulares alongados, um anterior e outro posterior ao núcleo, 15.0-20.0 X 5,0-15.0 $\mu \mathrm{m}$. outros menores. 4.0-6.0 X 2.0-3.0 $\mu \mathrm{m}$ dispersos no citoplasma; corpos mucíferos não observados; núcleo central, oblongo, ca. 18,0 X 9,0 $\mu \mathrm{m}$; estigma alongado, compacto. ca. 5.0 X 2,0 $\mu \mathrm{m}$; flagelo ca. 3/4 do comprimento da célula; metabolia pouco acentuada, ocorrendo principalmente nas regióes anterior e posterior da célula devido a curvaturas e torções da célula cistos e estádios palmelóides não observados.

Material examinado: R147080; R147081; R148120.

Distribuição geográfica no Estado do Rio de Janeiro: RIO DE JANEIRO: Manguinhos, Santa Cruz. Cascadura (Cunha. 1913a. 1913b: 17). PARAÍBA DO SUL. local não especificado (Cunha. 1913a. 1913b: 17), ARARUAMA: Lagoa de Juturnaíba (Huszar, 1986:81).

Euglena tripteris (Duj.) Klebs aproxima-se morfologicamente, de E. oxyuris Schmarda, E. pseudospiroides L.P. Johns., E. trissulcata L.P. Johns. e de E. fronsundulata L.P. Johns.

Euglena oxyuris Schmarda difere de E. tripteris (Duj.) Klebs pela secção transversal: elíptica na primeira e trirradiada na segunda. Euglena pseudospiroides L.P. Johns. difere de E. tripteris (Duj.) Klebs pela disposição dos cloroplastídios paralela às estrias do periplasto e pelo fato de as depressões entre os flancos da célula serem de difícil observação. Já $E$. trissulcata L.P. Johns. difere de E. tripteris (Duj.) Klebs pelo flagelo de menor tamanho, com menos da metade do comprimento da célula. pelos cloroplastídios menores com ca. 1.5 $\mu \mathrm{m}$ diâm.. pela torção da célula mencs pronunciada. com sulcos mais definidos. pelas dimensões celulares maiores, 205,0-220,0 $X \quad 11.0-15.0 \mu \mathrm{m}$ $(\overline{\mathrm{R}} \mathrm{c} / 1=14,6-18,6)$, bem como pelos grãos de paramido em forma de bastōes. nunca anulares como em $E$. tripteris (Duj.) Klebs. Euglena fronsundulata L.P. Johns. apresenta dimensões menores que E. tripteris (Duj.) Klebs, 42.0-53.0 X 4.0-7.0 $\mu \mathrm{m}$ apesar da maior $\mathrm{Rc} / 1(\overline{\mathrm{R}} \mathrm{c} / 1=7,6-10.5)$ e secção transversal em forma de "Y", além de sofrer abaulamento do pólo anterior durante a locomoção.

Goidics (1953) considera as três espécies de Johnson (1944) independentes. enquanto que Pringsheim (1956) coloca $E$. fronsundulata L.P. Johns. e $E$. trissulcata L.P. Johns. como táxons duvidosos. muito próximos a $E$. tripteris 
(Duj.) Klebs ou quase idênticos à ela e posiciona GE. pseudospiroides L.P. Johns. entre E. tripteris (Duj.) Klebs e E. oxyuris Schmarda.

No material procedente do Rio de Janeiro. tivemos a oportunidade de observar. na mesma amostra. algumas características diferenciais entre os táxons citados anteriormente. Nos indivíduos analisados. constatamos grãos de paramido ora sob a forma de bastões. ora de anéis alongados. $\mathrm{O}$ grau de torção da célula variou. bem como a profundidade dos sulcos. o que tornou a célula, quando em secção transversal. semelhante à letra "Y".

Tais observaçöes levam-nos a supor, como Pringsheim (1956), que $E$. fronsundulata L.P. Johns. e E. trissulcatd L.P. Johns. sejam muito próximas a $E$. tripteris (Duj. ) Klebs, pois as únicas diferenças reais entre elas estão nas dimensões celulares. Quanto a E. pseudospiroides L.P. Johns.. achamos estar mais próxima de $E$. oxyuris Schmarda, por apresentar secção transversal elíptica. ao contrário de $E$. tripteris (Duj.) Klebs, que a apresenta trirradiada.

Nossas algas apresentaram características morfológicas muito próximas às observadas por Pringsheim (1956) para E. tripteris (Duj.) Klebs, com a qual identificamos nosso material.

\section{Euglena viridis Ehr.}

Infus. 107. pl. 7. fig. 9. 1838.

(Fig. 42-46)

Células amplamente fusiformes, $33.0-44.0 \quad \mathrm{X} \quad 12.0-16.0 \mu \mathrm{m}$ $(\overline{\mathrm{R}} \mathrm{c} / 1=\mathrm{ca} .2 .7)$; pólo posterior atenuado gradativamente em processo caudal cônico. às vezes cilíndrico, hialino; periplasto com estrias finas. nítidas. espiraladas; cloropastídios numerosos, em finas radiais partindo da região central da célula, orientadas em diversas direções, 5,0-12,0 X 2,0-3,0 $\mu \mathrm{m}$; pirenóides ausentes. grãos de paramido numerosos. variando em dimensões, oblongos, poligonais, arredondados. concentrados na parte central da célula: corpos mucíferos arredondados. distribuídos no citoplasma: núcleo posterior. arredondado. ca. 3.0 $\mu \mathrm{m}$ diâm.: flagelo ca. do comprimento da célula. às vezes mais longo: metabolia acentuada. principalmente na parte mediana da célula. com forma em arco: sob irritacão química forma normamente esférica; cistos e estágios palmelóides não observados.

Material examinado: R147070; R147074; R147093; R147096; R148134; R148136.

Distribuicão geográfica no Estado do Rio de Janeiro: RIO DE JANEIRO: arredores de Manguinhos (Prowazek. 1910: 151): Manguinhos. Gávea (Cunha. 1913a. 1913b: 16): PARAÍBA DO SUL: local não especificado (Cunha. 1913a. 1913b: 16); RIO DE JANEIRO: Cidade das Meninas (Andrade. 1953: 103): Ilha dos Pinheiros (Oliveira et al. 1967: 121).

Conforme a literatura especializada. as espécies e variedades próximas a $E$. viridis Ehr. são as mais difíceis de se reconhecer e diferenciar. pois a estrutura interna da célula não se mostra nítida sob todas as circunstâncias. Além 
disto. a facilidade de modificação no plastidoma por influência ambientais implicam. necessariamente. em exame minucioso de razoável número de indivíduos.

Conforme a literatura especializada, as espécies e variedades próximas a $E$. viridis Ehr. são as mais difíceis de se reconhecer e diferenciar. pois a estrutura interna da célula não se mostra nítida sob todas as circunstâncias. Além disto. a facilidade de modificacão no plastidoma por influência ambientais implicam. necessariamente. em exame minucioso de razoável número de indivíduos.

Pringsheim (1956) discorda do grupamento ds "espécies viridóides" de Chadefaud (1939). aue se baseia na presenca e na natureza dos corpos mucíferos. alegando que tal grupamento não demonstra qualquer relacão natural. desde que tais estruturas dependem de condicões ambientais. No entanto. apesar de discordar das bases destes grupamento. Pringsheim (1956) incorre no mesmo erro de Chadefaud (1939) ao considerar $E$. pseudoviridis Chad. diferente de $E$. viridis Ehr.. pelo dato da primeira não apresentar corpos mucíferos evidentes e a segunda sim.

Euglena viridis Ehr. aproxima-se muito. morfologicamente. de E. stellate Mainx. Autores como Mainx (1926). Chadefaud (1939) e Pringsheim (1956) aceitaram $E$. stellata Mainx como uma boa espécie. diferindo-a de $E$. viridis Ehr. pela nítida estriacão do periplasto. presença de corpos mucíferos fusiformes. arranio estrelado do plastidoma menos definido e preferência por meio ácido.

Mais um vez chamamos a atenção para a delimitacão dos táxons baseados na presença de estriação do periplasto e de corpos mucíferos. pois estes apresentam-se muito instáveis quanto ao meio. devendo-se. então. tomar cautela na utilização desses caracteres na sistemática do grupo.

O material analisado do Rio de Janeiro apresentou-se bastante concordante com as características morfológicas da diagnose original desta espécie.

\section{Conclusões}

Das quase 150 amostras examinadas. procedentes de coletas efetuadas no Município do Rio de Janeiro e arredores. Estado do Rio de Janeiro. apenas 36 mostraram representantes pigmentados do gênero Euglena.

Foram identificados 17 táxons distribuídos em 14 espécies e 3 variedades. sendo que Euglena agilis H.J. Cart. foi táxon melhor representado em número de amostras. aparecendo em $22 \%$ das mesmas.

Dos 17 táxons identificados. apenas oito iá haviam sido anteriormente registrados para a área estudada. quais sejam: Euglena acus Ehr. var. acus. Euglena agilis H.J. Cart.. (como E. pisciformis Klebs). Euglena deses Ehr.. Euglena ehrenbergii Klebs. Euglena gracilis Klebs. Euglena spirogvra var. fusca Klebs (como E. fusca Klebs). Euglena viridis Klebs. Os demais táxons consti- 
tuem novas citacões de ocorrência no Estado do Rio de Janeiro.

Propõe-se. aue. apesar da descricão original de Klebs para Euglena pisciformis ser mais completa e seu nome mais utilizado na bibliografia especializada. deve prevalecer para a espécie a combinacão Euglena agilis H.J. Cart. sobre a primeira. pela sua maior antiguidade. embora sua descricão seia memos completa que a de Klebs.

Variacões observadas no número de grãos de paramido. no grau de torção celular, no espessamento e na intensidade da estriação do periplasto e no comprimento do flagelo, leva-nos a supor serem tais critérios insuficientes para a proposição e identificação de espécie e de categorias infra-específicas no gênero Euglena. Dessa maneira, estas características devem ser cuidadosamente estudadas em exemplares coletados na natureza e cultivados em laboratório, a fim de se efetuar uma análise crítica da validade destas expressões morfológicas na sistemática do grupo.

Ainda, a natureza do protoplasma, principalmente dos cloroplastídios e pirenóides, atua como principal critério na identificação e delimitação dos táxons infra-específicos do gênero Euglena. A deformação que as estruturas protoplasmáticas sofrem posteriormente à fixação e o acentuado grau de polimorfismo existente no grupo requerem, indubitavelmente, estudos de amostras populacionais vivas. Tal estudo possibilitará melhor caracterização da morfologia utilizada na sistemática desses táxons e estabelecerá um sistema mais natural na taxonomia dos mesmos.

\section{Agradecimentos}

Ao Dr. Carlos Eduardo de Mattos Bicudo e à Profa. Vera Lúcia de Moraes Huszar pela indispensável orientação.

\section{Referências Bibliográficas}

ALVARENGA, L.C.P. et alii. 1979. Resultados preliminares dos trabalhos ecológicos realizados na Lagoa de Juturnaíba, Município de Araruama, Estado do Rio de Janeiro, criadouro natural de bivalves Diplodon beskeanus (Dunker, 1849) (unioidea: Hyriidae) e Anodontites trapesealis (Lamark, 1819) (muteloidea: Mycotopidea). Anais V Enc. Malac. bras., Mossoró, p. 73-89.

ANDRADE, R.M. 1953. Observaçōes hidrobiológicas sobre o Anopheles tarsimaculatus, I: Relações com alguns organismos planctônicos. Revta. bras. Malar. Doenç. trop., Rio de Janeiro, 5 (11): 95-107.

ANDRADE, R.M. 1956. Observaçōes hidrobiológicas sobre o Anopheles tarsimaculatus, III: distribuição, frequência de ocorrência e densidade relativa de organismos plânctônicos em alguns dos biótopos. Revta. bras. Malar. Doenç. trop., Rio de Janeiro, 8 (3): 443-90.

ARAÚJO, D.S.D. \& MACIEL, N.D. 1979. Os manguezais do recôncavo da Baía de Guanabara. Cadernos FEEMA, Sér. técnica, Rio de Janeiro, 10: 1-113. 
ARAUJO, M.C.H. 1979. O problema do jacinto d'água na região de Jacarepaguá. Cadernos FEEMA. Sér. técnica, Rio de Janeiro, 8: 295-314.

BICUDO, C.E.M. \& BICUDO, R.M.T. 1970. Algas de águas continentais brasileiras: chave ilustrada para a identificação de gêneros. São Paulo, Editora da Universidade de São Paulo, 228p., il.

BOURRELLY, P. 1949. Euglena oxyuris Schmarda et formes affines. Bull. mus. Hist. nat:: Sér. 2, Paris, 21 (5): 612-16.

BOURRELLY, P. 1970. Les algues deau douce: iniciation à la systématique; 3: les algues bleues et rouges, les Eugleniens, Peridiniens et Cryptomonadines. 1. ed. Paris, Editions N. Boubée \& Cie. 3V., 512p., il.

CALAZANS, R. 1971. Esquistossomose - sua importância na problemática brasileira: com aspectos ecológicos em alguns focos de Planorbídeos no Estado de Guanabara. Publçöes Inst. Eng. sanit., Rio de Janeiro, 64: 1-24.

CARDOSO, M.C. 1982. Levantamento das Euglenaceae pigmentadas do Distrito Federal, Brasil. São Paulo, 289., il (Universidade de São Paulo, Tese de Doutorado em Botânica).

CARTER, H.L. 1856. Notes on the freshwater Infusoria on the Island of Bombay. I. Organization. Ann. Mag. nat. Hist., Sér 2, London, 18 (103): 115-132; (105): 221-248.

CHADEFAUD, M. 1939. Sur 1'organisation d' Euglena stellata Mainx et sur la discrimination des euglénes viridoides. Archs Zool. exp. gén., Paris, 80: 49-54.

CHU, S.P. 1946. Contributions to our Knowledge of the genus Euglena. Sinensia, Shangai, 17(1-6): 75-134.

CUNHA, A.M. 1913a. Contribuição para o conhecimento da fauna de protozoários do Brasil, Brasil, 1913a, 124p. (Tese de Cátedra. Universidade do Brasil).

CUNHA, A.M. 1913b. Contribuição ao conhecimento da fauna de protozoários do Brasil, Brasil. Rio de Janeiro, Gomes Irmão \& C. 100p. il.

CUNHA, A.M. 1913c. Contribuição para o conhecimento da fauna de protozoários do Brasil, Mems Inst. Oswaldo Cruz, Rio de Janeiro, 5:101-122.

CUNHA, A.M. 1914. Contribuição para o conhecimento da fauna de protozoários do Brasil. Mems Inst. Oswaldo Cruz, Rio de Janeiro, 6(3): 169-179.

DANGEARD, P. 1901. Recherches sur les Eugléniens. Botaniste, Paris, 8: 97-357, 1901.

DEFLANDRE, G. 1924a. A propos de l'Euglena acus Ehrenberg. Revue algol., Paris, 1: 235-43.

DEFLANDRE, G. 1924b. Additions à la flore algologique des environs de Paris. Bull Soc. bot. Fr., Paris, 24: 1115-1130.

DEFLANDRE, G. 1928. Algues d'eau douce du Venezuela (Flagellés et Chlorophycées recoltés par la Mission M. Gusol. Révue algol., Paris, 3: 212-241.

DUJARDIN, F.M. 1841. Histoire Naturelle des Zoophytes Infusiores. Paris, Roret. xii + 684p., il.

EHRENBERG, C.G. 1838. Die Infusionsthierchen als volkommende Organismen: Ein Blick in das tiefere organische Leben der Natur. Leipzig, Verlag von Leopold Voss. $\mathrm{xxii}+548 \mathrm{p}$.

GOJDICS, M. 1953. The genus Euglena. Madison, The University of Wisconsin Press, viii +268 p., il.

HÜBER-PESTALOZZI, G. 1955. Das Phytoplankton des Süsswassers: Systematik und Biologie: Euglenaceen. Stuttgart, E. Schweizerbart 'sche Verlagsbuchhandlung, v. 16 , ix $+606 .$, il. 
HUBNER E.F.W. 1886. Euglenaceen-flora von Stralsund. Program r. Strass., Stralsund, 20p.

HUSZAR. V.L.M. 1985. Algas planctônicas da Lagoa de Juturnaíba, Araruama, RJ, Brasil. Revta. bras. bot., São Paulo, 8: 1-19.

HUSZAR, V.L.M. 1986. Algas planctônicas da Lagoa de Juturnaíba, Araruama, RJ, Brasil, II. Rickia 13: 77-86.

HUSZAR, V.L.M. \& ESTEVES, F.A. 1988. Considerações sobre o fitoplâncton de rede de 14 lagoas costeiras do Estado do Rio de Janeiro. Acta Limnol. bras. 2: (323-346).

HUSZAR, V.L.M. et alii. 1988. Fitoplâncton da lagoa do Campelo, Campos, Rio de Janeiro, Brasil; uma contribuição a seu conhecimento Acta bot. brasil., Suppl 1(2): 209-219.

IYENGAR, M.O.P. 1962. Euglena studies from Madras. Arch. Mikrobiol., Berlon, Heidlberg, 42: 392-332.

JOHNSON, L.P. 1944. Euglenae of Iowa. Trans. Amer. microsc. Soc., Lancaster, 63: 97-135.

KLEBS, G. 1883. Über die Organisation einiger Flagellaten-gruppe und ihre Beziehungen zu Algen und Unfusorien. Unters. $d$. bot. Inst. Tübingen, 1: 233-362.

KOLKWITZ, R. 1933. Zur ökologie der Pflenzenwelt Brasiliens. Ber. dt. bot. Ges., Berlin, 51 (9): 396-406.

LEEDALE, G. 1967. Euglenoid Flagellates, Prentice-Hall, Inc., Englewood Cliffs, N.J., xiii + 242p., il.

LEFÉVRE, M. 1934. Recherches sur la bioligie et la systematique de quelques Eugléniens. Revue algol., Paris, 7 (1/2): 139-148.

LEMMERMANN, E. 1898. Beiträge zur Kenntnis der Planktonalgen II. Beschreibung neuer Formen. Beih. bot. Zbl., Cassel, 76: 150-156.

LEMMERMANN. E. 1910. Kryptogamenflora der Mark Brandenburg, III: algen I. (Schizophbyceen, Flagellaten, Peridineen): Leipzig, Verlag von Gebrüder Borntraeger. $712 \mathrm{p}$, il.

LEMMERMANN, E. 1913. Eugleninae. In: PASCHER, A. Süsswasserflora Österreichs und der Schweiz. Jena, Gustav Fischer Verlag, v. 2, 115-174.

MAINX, F. 1926. Einige neue Vertreter der Gattung Euglena Ehrenberg nut Unterstützung der Gesellschaft zur Förderung deutschen Wissenschaft, Kunst und Literatur in Bönhmen. Arch. Protistenk., Jena, 54: 150-160.

MENEZES, M. 1987. Polimorfismo em Lepocinclis ovum (Ehrenberg) Lemmermann e suas implicações taxonômicas. Rickia. 14: 1-6.

MIGNOT, J.P. 1967. Quelques observations sur une Euglene du Creux de pisseport: Euglena splendens Dangeard, 1901. Annls Stn. biol. Besse - en-Chandesse, Clermont-Ferrand, 2: 161-174.

OLIVEIRA, L.P.H. et alii. 1951. Contribuição ao estudo hidrobiológico dos criadouros de Anopheles tarsimaculatus Goeldi, 1905 (=Anopheles aquasalis Curry, 1932) na Baixada fluminense. Revta. bras. Malar. Doenç. trop., Rio de Janeiro, 3 (2): 149-247.

OLIVEIRA, L.P.H. et alii. 1967. Plancto e hidrobiologia sanitária de tanques tropicais com dáfnias e rotíferos. Mems. Inst. Oswaldo Cruz, Rio de Janeiro, 65 (2): 115-147.

PALMER, C.M. 1969. A composite rating of algae tolerating organic pollution. J. Phycol., Lawrence, 5: 78-82. 
PEIXOTO, J.A. \& HUSZAR, V.L.M. 1983. Algümas espécies de algas da Quinta da Boa Vista, Rio de Janeiro. Bol. Mus. nac. Rio de J., Nova Sér. Bot., Rio de Janeiro, 67: 1-8.

PERTY, M. 1852. Zur Kenntnis Kleinster Lebensformen nach Bau, Funktionen, Systematik mit Spezialverzeichnis der in der Schweiz beobacteten. Bern, Verlag von Jent und Reinert, viii + 228p., il.

PLAYFAIR, G.I. 1921. Autralian Freshwater flagellates. Proc. Linn. Soc. N.S. W., Sydney, 46 (1): 99-146.

PRESCOTT, G.W. 1944. New species and varietes of Wisconsin algae. Farlowia, Cambridge, 1 (3): $347-373$.

PRINGSHEIM, E.G. 1948. Taxonomic problems in the Eugleninae. Biol. Rev., Cambridge, 23: 46-61.

PRINGSHEIM, E.G. 1956. Contribution towards a monography of the genus Euglena. Nova acta Leopoldina, Leipzig, 18: 1-168.

PRITCHARD, A. 1852. A history of Insuforial Animacules. London, Whitaker and Co., viii $+704 \mathrm{p}$.

PROWASEK, S. 1910. Contribuição para o conhecimento da fauna de protozoários do Brasil. Mems. Inst. Oswaldo Cruz, Rio de Janeiro, 2 (2): 149-158.

ROUND, F.E. 1973. The biology of the algae. 2. ed. London, Edward Arnold Ltd. 278., il.

SAMPAIO, G.F. 1984. Lista dos criptógamos avasculares encontrados na Lagoa Rodrigo de Freitas por biólogos da FEEMA. In: CARAUTA, J.P.P. \& VIANNA, M.C. A Lagoa Rodrigo de Freitas: sinopse histórica e plantas marginais. Atas Soc. bot. Brasil, Rio de Janeiro, 2 (6): 45-49.

SEMERARO, J. \& COSTA, A.F. 1972. Plancton e a poluição das Lagoas da Tijuca, Camorim e Jacarepaguá. Publçôes Inst. Eng. sanit., Rio de Janeiro, 73: 1-31.

SCHMARDA, L.K. 1846. Kleine Beiträge zur Naturgeschichte der Infusorien. Wien, Verlag der Carl Haas' schen Buchhandeung, vi + 61p.

SCHMITZ, F. 1884. Beiträge zur Kenntnis der Chromatophoren. Jb. Wiss. Bot., Berlin, 15: 1-175.

SKUJA, H. 1948. H. Taxonomie des Phytoplankton einiger seen in Uppland, Schwede. Symb. bot. upsal., Uppsala, 9 (13): 1-399.

SKUJA, H. 1956. Taxonomische und biologische studien Über das Phytoplanktion schwedischer Binnengewasser. Nova Acta R. Soc. Scient. upsal., Sér. 4, Uppsala, 16: $1-404$.

SKVURTZOV, B. 1967. New and interesting species of Euglena Ehr. from the subtropics of Brasil. Nova Hedwigia, Weinheim, 14: 379-386.

STAFLEU, F.A. et alii. 1978. International Code of Botanical Nomenclature. Utrecht, Bohn, Scheltema \& Hoekama. xiv $+1-457 p$. (12을 Congresso Internacional de Botânica, Leningrado, 1975).

STEIN, F.R. 1878. Der Organismus der Infusionsthiere, III. Der Organismus der Flagellaten I. Leipsig, 154p.

SWIRENKO, D.O. 1913. Beiträge zur Kenntnis der Flagellatenflora der Umgegend der Stadt Charpow. Trav. Soc. nat. Univ. Imp., Kharpow, 64: 67-90.

SWIRENKO, D.O. 1915. Zur Kenntnis der russischen Algenflora II. Euglenaceae (excl. Trachelomonas). Arch. Hydrobiol. Planktonk., Struttgart, 10: 321-340.

VAN OYE, P. 1924. Note sur IEuglena acus Ehrbg. Bull. Soc. r. Bot. Belg., Bruxelles, 56 (2): 1-9. 


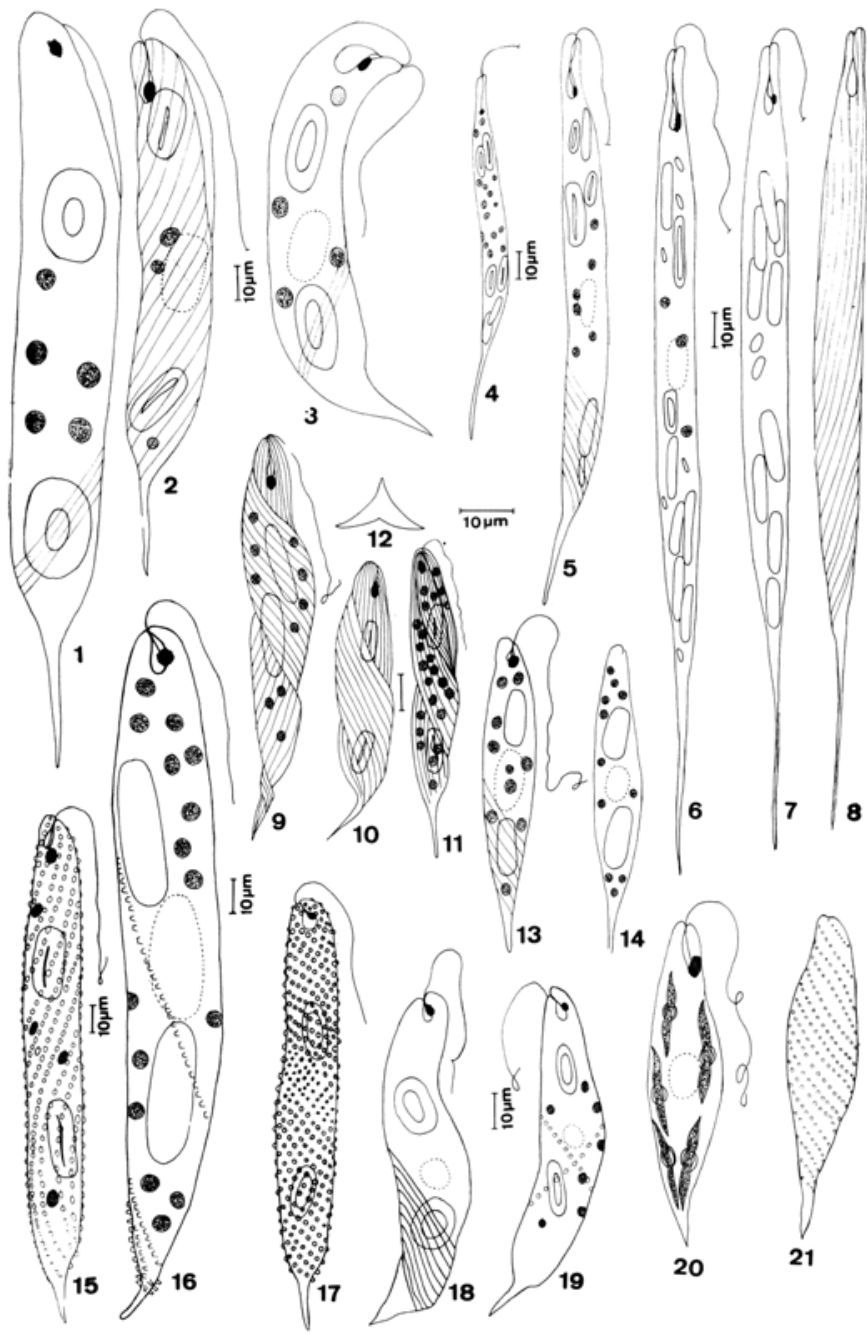

Fig. 1-3 - Euglena oxyuris Schmarda var. charkowiensis (Swir.) Chu.

Fig. 4-5 - Euglena acus Ehr. var. acus.

Fig. 6-8 - Euglena acus Ehr. var. longissima Defl.

Fig. 9-12 - Euglena tripteris (Duj.) Klebs.

Fig. 13-14 - Euglena limnophila Lemm.

Fig. 15-16-Euglena spirogyra Ehr. var. fusca Klebs.

Fig. 17-19-Euglena spirogyra Ehr. var. spirogyra.

Fig. 20-21 - Euglena granulata (Klebs) Schmitz. 


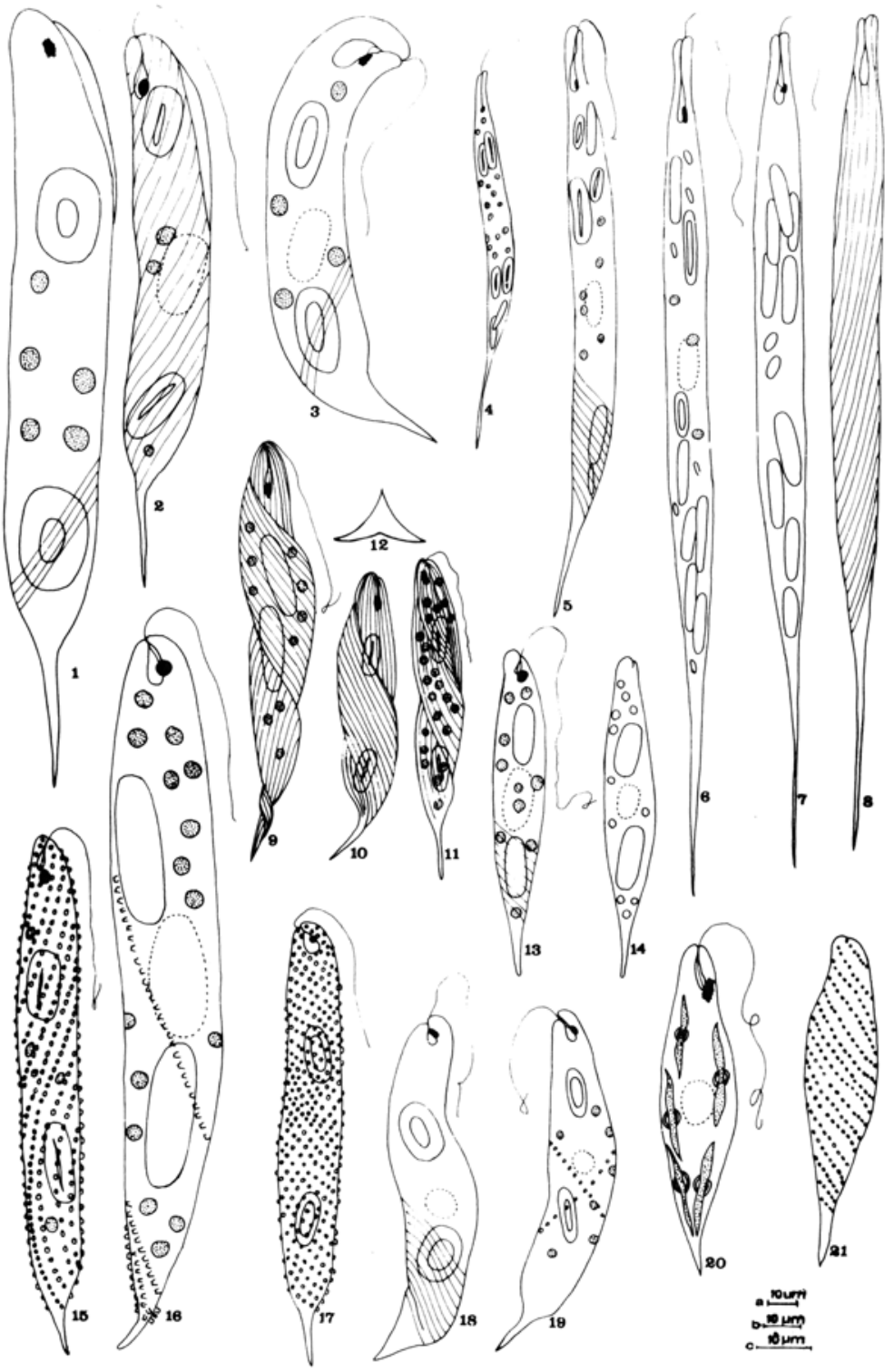

Figuras 4, 15 - escala a

Figuras 1, 9, 12, 13, 14, 20 e 21 - escala c

Demais figuras - escala b 


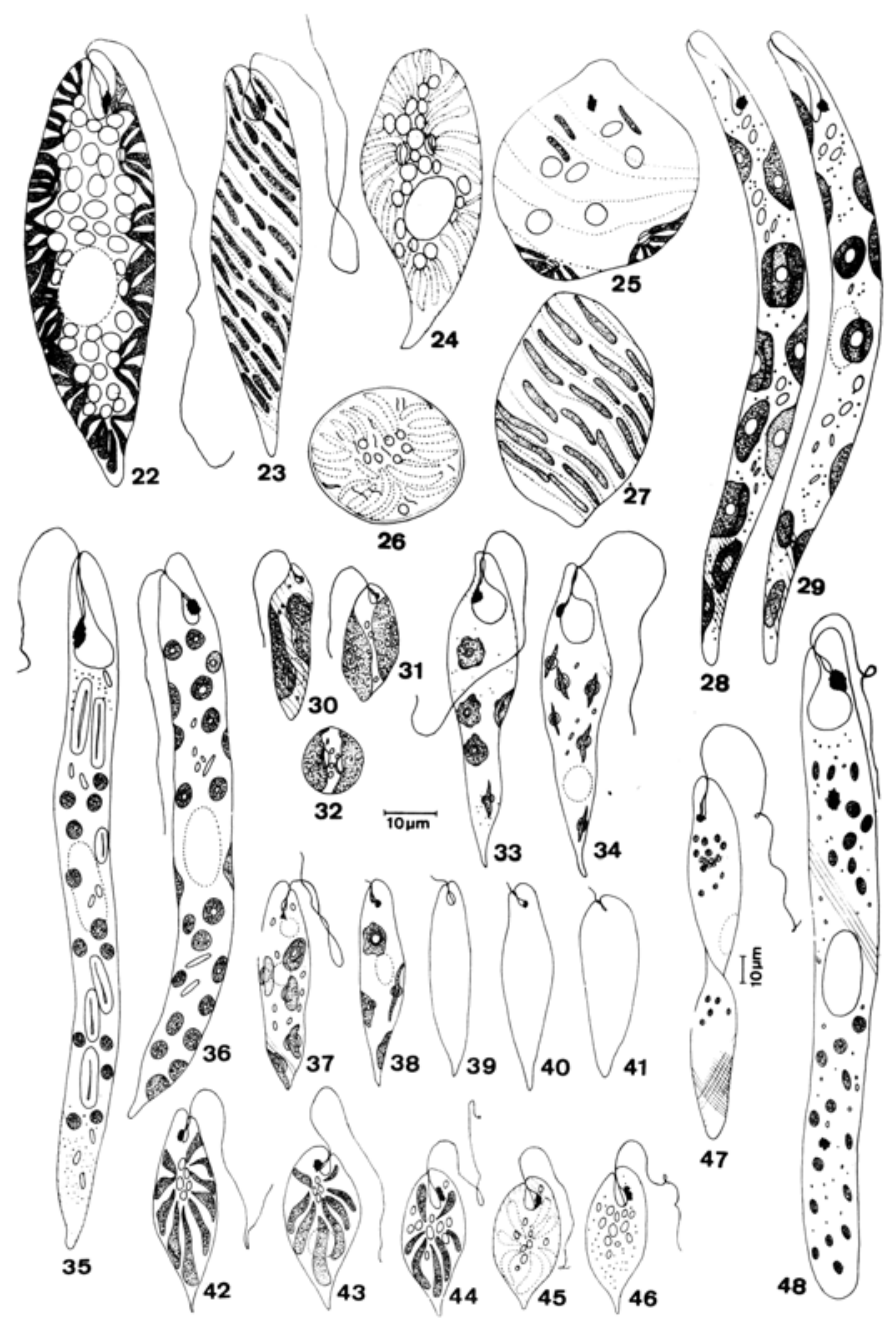

Fig. 22-27 - Euglena splendens Dang.

Fig. 28-29 - Euglena mutabilis Schmitz. var. mutabilis

Fig. 30-32 - Euglena agilis H.J. Cart.

Fig. 33-34 - Euglena caudata Hübn.

Fig. 35 - Euglena intermedia (Klebs) Schmitz.

Fig. $36-$ Euglena deses Ehr.

Fig. 37-41 - Euglena gracilis Klebs.

Fig. 42-46 - Euglena viridis Ehr.; 46 - grãos de paramido e corpos mucíferos.

Fig. 47-48-Euglena ehrenbergii Klebs. 


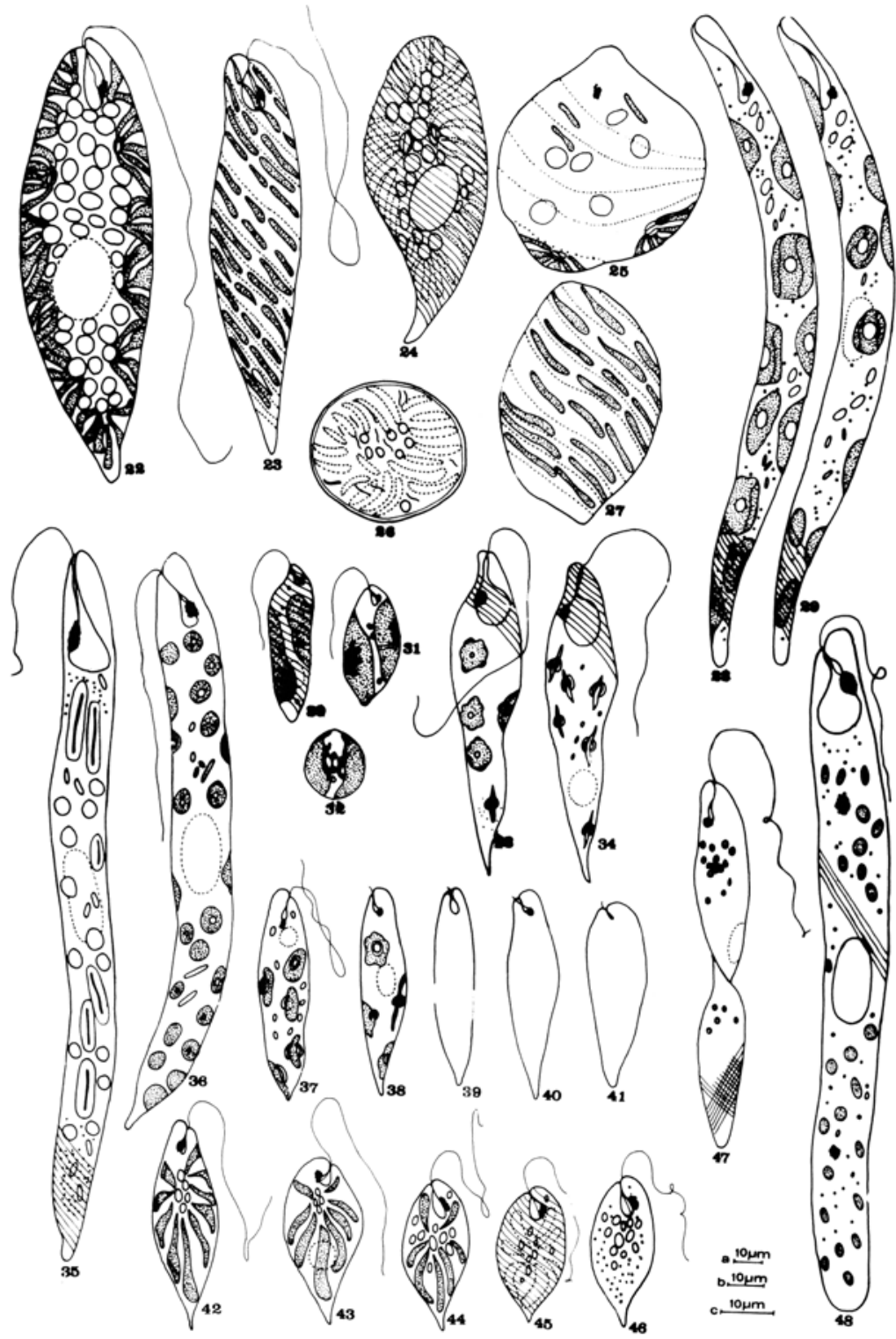

Figura 47 - escala a

Figura 35 - escala b

Demais figuras - escala c 


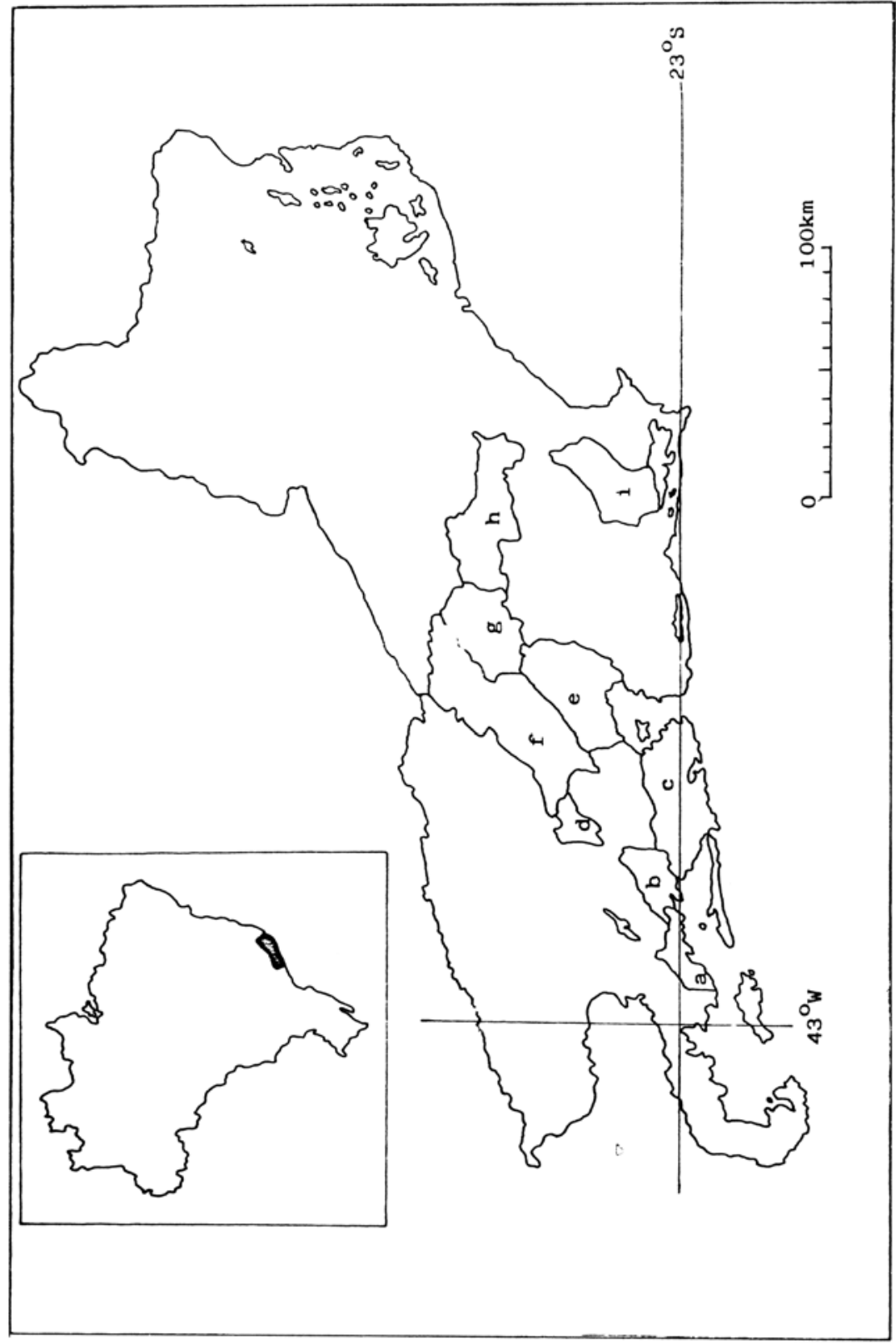

Mapa 1 - Estado do Rio de Janeiro, indicado os Municípios de coletas. 


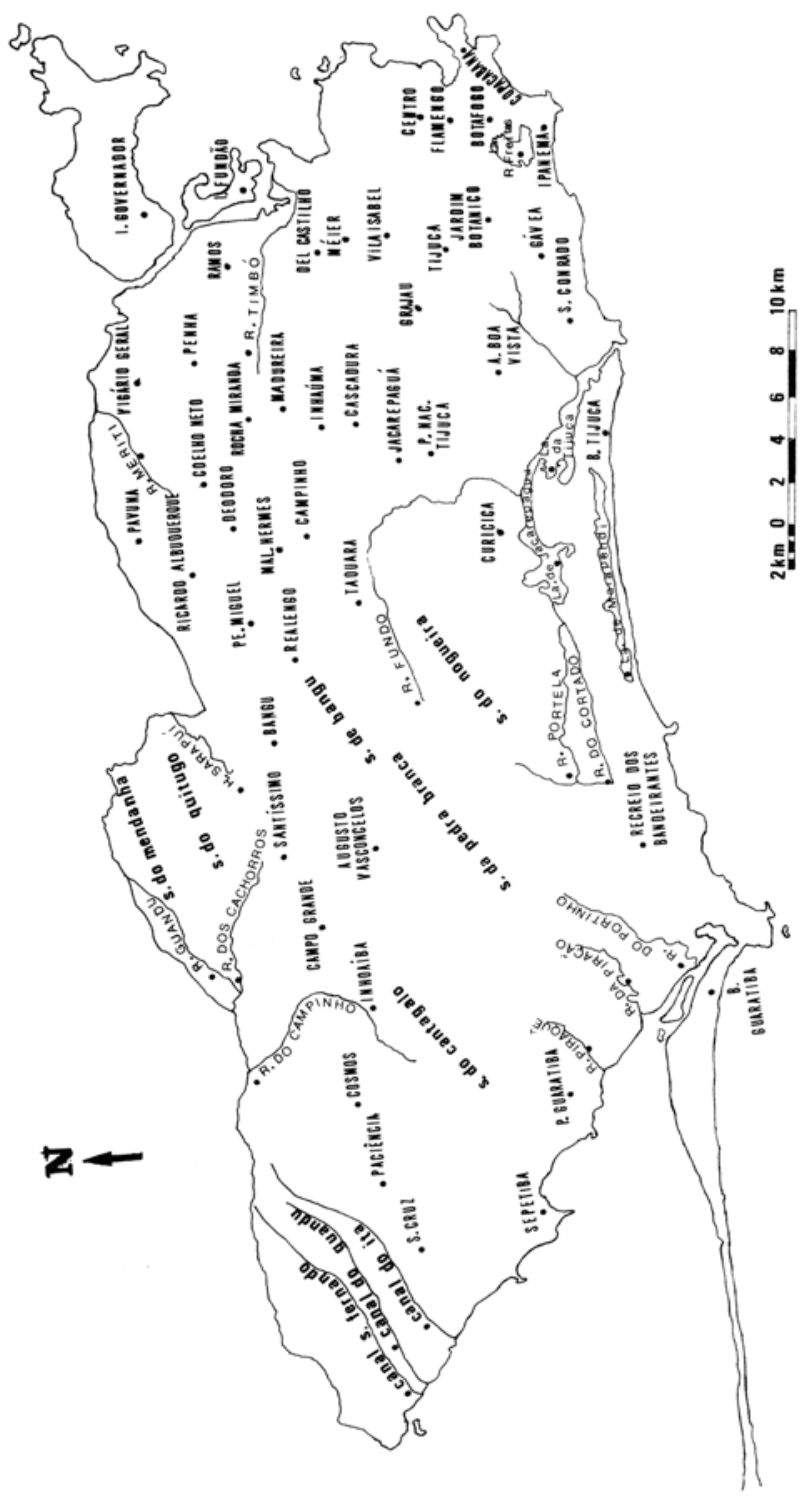

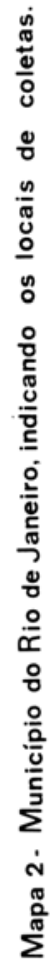

Mapa 2 - Município do Rio de Janeiro, indicado os locais de coleta. 